\title{
Corrosion Performance of Carbon Steel in Simulated Pore Solution in the Presence of Micelles
}

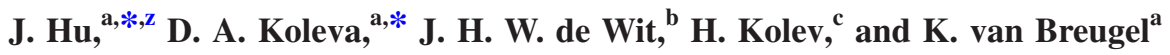 \\ ${ }^{a}$ Faculty of Civil Engineering and Geosciences, Materials and Environment, Deft University of Technology, \\ 2628 CN Delft, The Netherlands \\ ${ }^{b}$ Faculty 3mE, Department Surfaces and Interfaces, Deft University of Technology, 2628 CD Delft, \\ The Netherlands \\ ${ }^{c}$ Bulgarian Academy of Sciences, Institute of Catalysis, Sofia, Bulgaria
}

\begin{abstract}
This study presents the results on the investigation of the corrosion behavior of carbon steel in model alkaline medium in the presence of very low concentration of polymeric nanoaggregates $\left[0.0024 \mathrm{wt} \%\right.$ polyethylene oxide $(\mathrm{PEO})_{113}$-b-PS ${ }_{70}$ micelles]. The steel electrodes were investigated in chloride-free and chloride-containing cement extracts. The electrochemical measurements (electrochemical impedance spectroscopy and potentiodynamic polarization) indicate that the presence of micelles alters the composition of the surface layers (i.e., micelles were indeed absorbed to the steel surface) and influences the electrochemical behavior of the steel, i.e., the micelles lead to an initially increased corrosion resistance of the steel whereas no significant improvement was observed within longer immersion periods. Surface analysis, performed by environmental scanning electronic microscopy, energy-dispersive x-ray analysis, and x-ray photoelectron spectroscopy, supports and elucidates the corrosion performance. The product layers in the micelles-containing specimens are more homogenous and compact, presenting protective $\alpha-\mathrm{Fe}_{2} \mathrm{O}_{3}$ and/or $\mathrm{Fe}_{3} \mathrm{O}_{4}$, whereas the product layers in the micelles-free specimens exhibit mainly $\mathrm{FeOOH}, \mathrm{FeO}$, and $\mathrm{FeCO}$, which are prone to chloride attack. Therefore, the increased "barrier effects" along with the layers composition and altered surface morphology denote for the initially increased corrosion resistance of the steel in chloride-containing alkaline medium in the presence of micelles.

(C) 2011 The Electrochemical Society. [DOI: 10.1149/1.3534796] All rights reserved.
\end{abstract}

Manuscript submitted August 27, 2010; revised manuscript received December 8, 2010. Published January 20, 2011. This was

Paper 888 presented at the Vancouver, Canada, Meeting of the Society, April 25-30, 2010.

A well-known fact is that corrosion of steel reinforcement can cause reinforced concrete deterioration and thus affect civil structures durability. ${ }^{1,2}$ Logically, corrosion-related issues result in a significant economic loss. For example, in the United States, the annual direct cost of bridge infrastructure corrosion was estimated to be $\$ 8.3$ billion, and the indirect cost was reported to be many times higher. $^{3}$

In normal conditions, the reinforcing steel embedded in cementbased materials (i.e., cement paste, mortar, and concrete) is in a passive state because of the high alkalinity $(p \mathrm{H}=12.6-13.5)$ of the pore solution and the cement paste, respectively. ${ }^{4,5}$ However, corrosion can be initiated due to carbonation or chloride contamination. ${ }^{6}$ Carbonation can result in a $p \mathrm{H}$ drop (to about $8-9)^{7,8}$ in the pore solution of the bulk cementitious matrix, leading to a general corrosion of the reinforcing steel. In the event of chloride penetration and chloride arrival at the steel/cement paste interface, localized corrosion is initiated; the local $p \mathrm{H}$ can drop to even below 6 , resulting in fast corrosion propagation. This will cause accelerated damage of the reinforcing steel and possible rapid failure of reinforced concrete. ${ }^{9}$

To minimize the corrosion processes, various methods and techniques are used. Among them, the polymer-based organic corrosion inhibitors are widely applied because they can provide an easy handling, cost-effective corrosion prevention, delaying corrosion initiation. ${ }^{10-14}$ The organic inhibitors are typically based on mixtures of alkanolamines and amines or amino acids or alternately on organic acids. ${ }^{15-22}$ They can work either on initiation period of time (increasing chloride threshold value or reducing chloride penetration rate) or on propagation period, reducing corrosion rate. ${ }^{10,23}$ The application of organic inhibitors were widely investigated both in concrete $^{24,25}$ and in simulated pore solution. ${ }^{26,27}$ However, there are still conflicting opinions about the effectiveness of organic inhibitors on reinforcement corrosion protection; ${ }^{28-31}$ different mechanisms are also reported: Some investigations illustrate that organic inhibitors are able to form an adsorbed layer on the steel surface, hindering steel dissolution. ${ }^{32}$ It is also suggested that organic inhibitors can

\footnotetext{
* Electrochemical Society Active Member

z E-mail: j.hu@tudelft.nl
}

block the anodic and cathodic reactions. ${ }^{21,33,34}$ Other authors report that organic inhibitors decrease the chloride content and chloride diffusion in concrete. ${ }^{34-36}$

Aiming at establishing novel approaches to corrosion control, this work presents initial tests, performed within a nontraditional investigation, involving the application of polymeric nanoaggregates in reinforced concrete. The present study is part of a 2-year research project on self-healing of corrosion damages in reinforced concrete, by tailoring the material properties of both steel and concrete via initially admixed micelles and/or vesicles. The nanoaggregates are not meant to have inhibiting effects on the corrosion initiation in the sense that organic inhibitors work, for example, but to release certain compounds, i.e., the so called "active substance," which would modify the pore solution and the steel/cement paste interface in a way, so that restoration of the original environment takes place (e.g., release of alkaline compound that would restore $p \mathrm{H})$. The release of "active substance" is foreseen to be triggered by changes in $p \mathrm{H}$. Preliminary research has been conducted with several types of nanoaggregates-micelles, vesicles, and hybrid aggregates (in model solutions, in cement pastes, and in mortar). ${ }^{37-40}$ The nanoaggregates themselves are not subject to extensive presentation and discussion. However, because the presence of nanoaggregates in a reinforced cement-based system would inevitably affect the bulk matrix (which would be prior to or simultaneously with affecting the embedded steel), the influence of the incorporated nanoaggregates on the bulk properties of cement-based materials is briefly presented below. Moreover, shortly presenting the results from these initial tests clarifies the aims and need for the present investigation.

The properties of the bulk cement-based matrix, containing polyethylene oxide (PEO-block-polystyrene (PS) ( $\mathrm{PEO}_{113}$-b-PS $\left.{ }_{218}\right)$ core-shell micelles with concentration of $0.5 \mathrm{~g} / \mathrm{L}$ mixing water (which is 0.006 wt \% per mortar weight), were previously investigated in plain (not reinforced) and in reinforced mortar specimens. ${ }^{37-39}$ It was found out that even a very low concentration of the micelles induces a significant reduction of porosity (about two times at early hydration stages) and water permeability K (m/s) (approximately 6 orders of magnitude) of the matrix. The recorded coefficient of $\mathrm{NaCl}$ permeability, however, was quite different for both micelles-containing and micelles-free groups. For the former (micelles-containing) group, permeability increases in the presence 
of $\mathrm{NaCl}\left(\mathrm{K}_{\mathrm{NaCl}}=1.1 \mathrm{e}^{-10} \mathrm{~m} / \mathrm{s}\right)$, while it decreases for the latter (micelles-free) group $\left(\mathrm{K}_{\mathrm{NaCl}}=6.09 \mathrm{e}^{-9} \mathrm{~m} / \mathrm{s}\right)$. For the micelles-free mixture, $\mathrm{NaCl}$ permeability is reduced, compared to water permeability, due to well-known chloride binding mechanisms, morphological, and structural modifications of the bulk matrix. ${ }^{41,42}$ For the micelles-containing specimens, although similar binding mechanisms and structural alterations should be taking place in the presence of $\mathrm{NaCl}$, permeability increases as a result of "shrinkage" of the polymer shell (PEO) of the micelles. ${ }^{43}$ In the latter case, although $\mathrm{NaCl}$ permeability was lower, compared to mixtures without micelles, the remaining question is whether corrosion resistance of the steel reinforcement in the modified matrix will be increased, compared to the micelles-free specimens. The previously reported results ${ }^{39,40}$ show a decreased corrosion initiation and propagation in the micelles-modified matrix. Further, tests on carbon steel in model alkaline solutions, where hybrid aggregates were added in a concentration of $4.9 .10^{-4} \mathrm{~g} / \mathrm{L}$ (hybrid formations, synthesized through a layer-by-layer adsorption of oppositely charged ployelectrolytes \{PDADMAC [poly(diallyldimethyl ammonium chloride)]/PAA [poly(acrylic acid)]/PDADMAC on $\mathrm{CaO}$ crystals $\}$ also resulted in an improved corrosion resistance of the steel electrodes. ${ }^{44}$

These preliminary investigations did not fully reveal whether the nanoaggregates were indeed present at the steel/cement paste interface and/or on the steel surface (considering the nanosize of the formations and the variety of cement hydration/corrosion products on the steel surface). Although steel corrosion in cement-based materials was substantially studied and results were reported (including some of the present authors), ${ }^{45-47}$ the remaining fact is that the system reinforced mortar (and concrete, respectively) is highly heterogeneous and complicated by itself. Therefore, the presence of nanoaggregates (as hereby discussed) leads to even more complexity in deriving electrochemical response for the steel reinforcement or within the steel surface analysis.

To this end and in order to minimize the influence of the surrounding cement matrix, the present investigation focuses on the effect of polymeric nanoaggregates on the steel corrosion performance in model solutions, simulating the pore solution of the bulk cementitious matrix. The paper comprises two main parts: electrochemical behavior of the steel electrodes in the relevant medium and surface analysis of the steel electrodes after treatment. The results of this study will act as preliminary data for the ongoing investigation in reinforced mortar in the presence of micelles and vesicles with tailored properties.

\section{Materials and Methods}

Materials. - Steel electrodes.-Low-carbon steel (St37) electrodes with a surface area of $0.65 \mathrm{~cm}^{2}$ were used; all electrodes were equally treated prior to investigation in the model medium, i.e., they were grinded with no. 500 to no. 4000 grinding papers and polished; further, just before immersion in the relevant solutions, they were cleaned with acetone.

Cement extract.- The cement extract (simulated cement pore solution) was prepared from ordinary portland cement OPC CEM I $42.5 \mathrm{~N}$ and tap water by mixing in the weight ratio of $1: 1$; the suspension was filtrated after $24 \mathrm{~h}$ rotation, and thus a simulated pore solution (CE) was obtained. The $p \mathrm{H}$ of $\mathrm{CE}$ is 12.6-12.9. The chemical composition (wt \%) of OPC CEM I $42.5 \mathrm{~N}$ (ENCI, NL) is as follows: $\mathrm{CaO}$ 63.9\%; $\mathrm{SiO}_{2} 20.6 \% ; \mathrm{Al}_{2} \mathrm{O}_{3} 5.01 \% ; \mathrm{Fe}_{2} \mathrm{O}_{3} 3.25 \% ; \mathrm{SO}_{3}$ $2.68 \%$; $\mathrm{K}_{2} \mathrm{O} 0.65 \%$; and $\mathrm{Na}_{2} \mathrm{O} 0.3 \%$. The chemical composition of the $\mathrm{CE}$ [derived chemically by inductively coupled plasma (ICP) analysis] is as follows: $\mathrm{Ca}, 201 \mathrm{mg} / \mathrm{L} ; \mathrm{K}, 3.85 \mathrm{mg} / \mathrm{L}$; $\mathrm{Na}$, $1.33 \mathrm{mg} / \mathrm{L} ; \mathrm{Al}, 4 \mathrm{mg} / \mathrm{L}$; and $\mathrm{Fe},<1 \mathrm{mg} / \mathrm{L}$. The originally received $\mathrm{CE}$ (modified and prepared) was the environmental medium for testing the electrochemical behavior of the steel electrodes. The CE modification was in terms of adding micelles (details specified below) and/or $\mathrm{NaCl}(10 \mathrm{~g} / \mathrm{L})$, thus ending up with four solution types: $\mathrm{CE}$ only (as control case); $\mathrm{CE}+$ micelles; $\mathrm{CE}+\mathrm{NaCl}$; and $\mathrm{CE}$

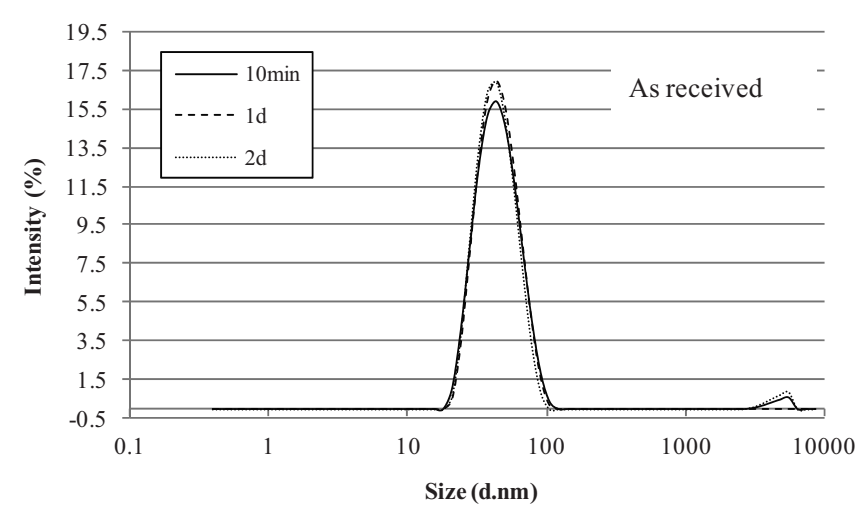

Figure 1. DLS of the micelles solution as received.

+ micelles $+\mathrm{NaCl}$. The so received solutions determine the samples groups and designation, which is provided further below.

Polymeric nanoaggregates. - The nanoaggregates employed in this study were prepared from $\mathrm{PEO}_{113}$-b-PS 70 diblock copolymer. The copolymer was synthesized by atom transfer radical polymerization (ATRP), employing the macroinitiator technique. ${ }^{48} \mathrm{PEO}_{113}-\mathrm{b}-\mathrm{PS}_{70}$ micelles in aqueous media were obtained by dialysis method. The aqueous solution of $\mathrm{PEO}_{113}-\mathrm{b}-\mathrm{PS}_{70}$ micelles (micelles concentration of $0.5 \mathrm{~g} / \mathrm{L}$ ), was added to a part of the cement extracts (specimens $\mathrm{CN}$ and $\mathrm{CNC}$ below), thus $0.0024 \mathrm{wt} \%$ of the micelles were present in chloride-free and chloride-containing cement extracts. The $\mathrm{PEO}_{113}$-b-PS 70 micelles are amphiphilic formations, presenting a hydrophilic PEO shell and a hydrophobic PS core. Dynamic light scattering (DLS) measurement was performed for the as-received micelles solution in order to determine their hydrodynamic radius and stability. Figure 1 presents the DLS measurement results at different time intervals (10 min, 1 day and 2 days), showing an apparent average hydrodynamic radius of $50 \mathrm{~nm}$ at all time intervals.

Sample designation.- As aforementioned, there were totally four testing solutions in this study. The samples designations are control groups " $\mathrm{C}$ " (without micelles) and "CN" (with micelles) and corroding groups "CC" (without micelles) and "CNC" (with micelles) (for the "corroding" cases, $\mathrm{NaCl}$ was added to the $\mathrm{CE}$ in concentration of $10 \mathrm{~g} / \mathrm{L})$.

Methods.-Electrochemical measurements.-The hereby employed electrochemical methods are: electrochemical impedance spectroscopy (EIS) and potentiodynamic polarization (PDP). A common three-electrode electrochemical cell [saturated calomel electrode (SCE) as reference] was used, and the measurements were performed after open-circuit potential (OCP) stabilization for all cells (the electrochemical measurements (as well as OCP readings) were performed on at least three replicates per sample type per age). The PDP measurement was performed in the range of -0.2 to $+1.2 \mathrm{~V}$ vs OCP at scan rate $0.5 \mathrm{mV} / \mathrm{s}$. The EIS measurements were carried out in the frequency range of $50 \mathrm{kHz}$ to $10 \mathrm{mHz}$ by superimposing an ac voltage of $10 \mathrm{mV}$. The used equipment was EcoChemie Autolab-Potentiostat PGSTAT30, combined with FRA2 module, using GPES and FRA interface.

Surface analysis.-For the relevant morphological aspects, qualification-quantification, and semiquantification analyses of the product layers (a mixture of iron oxides/hydroxides, micelles, and oxides/hydroxides of alkaline metals from the cement extract), formed on the steel surface in each medium, the steel electrodes were examined via scanning electronic microscopy (SEM), using environmental SEM (ESEM Philips XL30), coupled with energy dispersive-ray analysis (EDX), operating at an accelerating voltage of $5-20 \mathrm{kV}$. The EDX analysis was conducted in a local area of $50 \times 50 \mu \mathrm{m}$ at a magnification of 500 times). The EDX results were the average value of three locations per each sample. Further, surface analysis was performed by X-ray photoelectron spectros- 


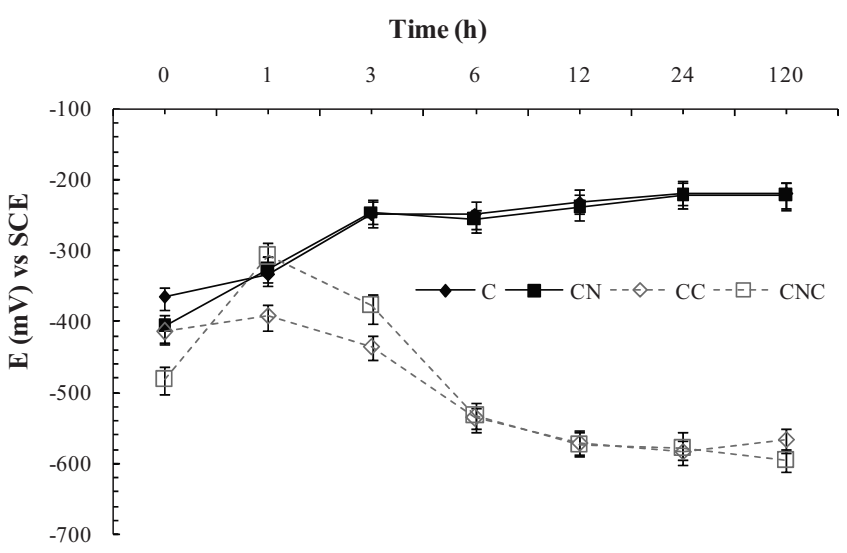

Figure 2. OCP readings of steel electrodes for all studied solutions.

copy (XPS). The XPS measurements were carried out in the UHV chamber of an electron spectrometer ESCALAB-MkII (VG Scientific) with a base pressure of about $1 \times 10^{-10}$ mbar (during the measurement $\left.1 \times 10^{-9} \mathrm{mbar}\right)$. The photoelectron spectra were obtained using unmonochromatized $\mathrm{Al} \mathrm{K} \alpha(h v=1486.6 \mathrm{eV})$ radiation. Passing through $6 \mathrm{~mm}$ slit (entrance/exit) of a hemispherical analyzer, electrons with energy $20 \mathrm{eV}$ are detected by a channeltron. The instrumental resolution measured as the full width at a halfmaximum (fwhm) of the $\mathrm{Ag} 3 \mathrm{~d}_{5 / 2}$, photoelectron peak is about $1 \mathrm{eV}$. The energy scale is corrected to the $\mathrm{C} 1 \mathrm{~s}$-peak maximum at $285 \mathrm{eV}$ for electrostatic sample charging. The fitting of the recorded XPS spectra was performed, using a symmetrical Gauss-Lorentzian curve fitting after Shirley-type subtraction of the background.

\section{Results and Discussion}

Electrochemical response.- OCP mapping.- In general, ОСP mapping determines the time to corrosion initiation. In chloridecontaining medium, corrosion initiation is due to the passive layer breakdown on the steel surface, i.e., localized corrosion. For the reinforced concrete (and model pore solution, respectively), the steel surface is considered passive if OCP is equal or more anodic than $-270 \mathrm{mV}$. $^{49-51}$

Figure 2 shows the OCP evolution for the steel electrodes in the testing solutions (readings are the average value of three samples per condition; deviation also depicted in the plot). As can be observed, the micelles did not significantly influence the OCP of the steel for the control groups (specimens $\mathrm{C}$ and $\mathrm{CN}$ ); both specimens showed OCP values more anodic than $-270 \mathrm{mV}$, i.e., a stable passive layer formed on the steel surface in the chloride-free cement extracts (both with and without micelles). For the corroding groups (specimens $\mathrm{CC}$ and $\mathrm{CNC}$ ), a positive effect was observed for the steel immersed in the micelles-containing cement extract (specimen $\mathrm{CNC}$ ) but only at earlier stages $(1$ and $3 \mathrm{~h})$, evidenced by more anodic OCP values. Within continued treatment, there was no obvious difference in OCP values. The result indicates that the presence of micelles in the chloride-containing cement extract causes a delay in the corrosion initiation.

EIS.-EIS is a widely applied electrochemical technique for studying the corrosion performance of steel in both reinforced concrete and simulated pore solution. ${ }^{52-55}$ Figures 3 and 4 depict an overlay of the EIS responses of the steel electrodes with the time of immersion in cement extract (micelle-free and micelle-containing solutions). Figure 3 presents the response for control cells C (Fig. 3a) and CN (Fig. 3b) from 1 to $24 \mathrm{~h}$; similarly, Fig. 4 depicts the response for the corroding cells CC and CNC (Figs. 4a and 4b), respectively.
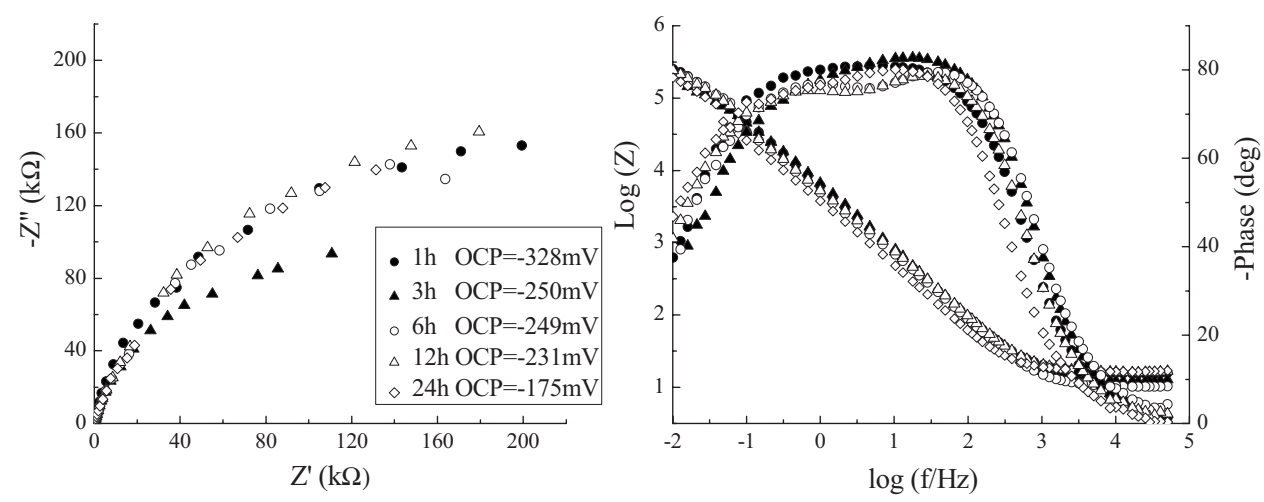

(a) Specimen $\mathrm{C}$
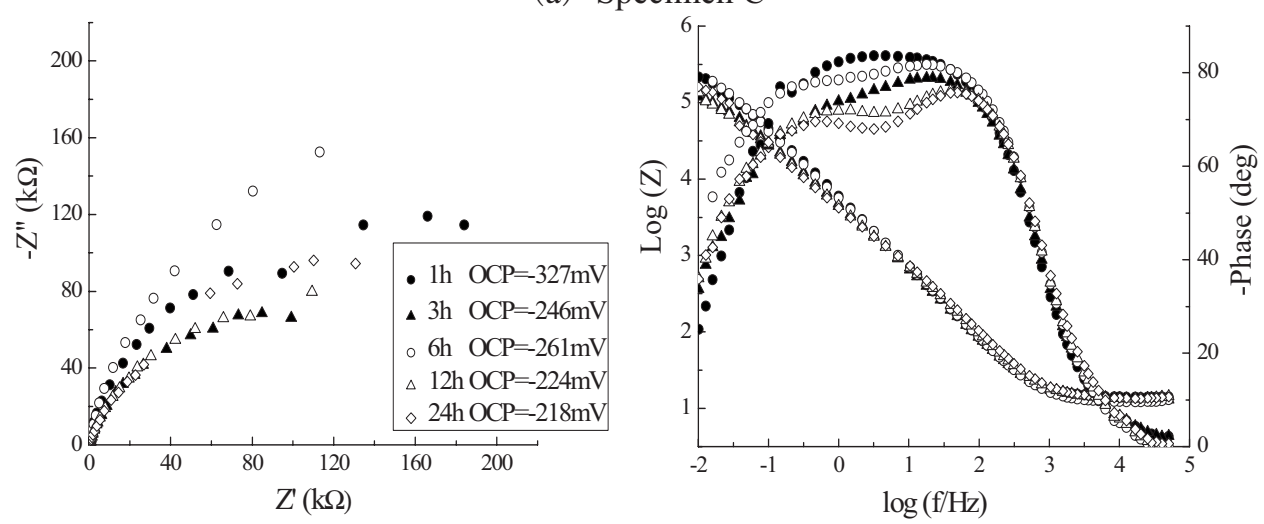

(b) Specimen $\mathrm{CN}$
Figure 3. EIS response in Nyquist and Bode format for control specimens. 


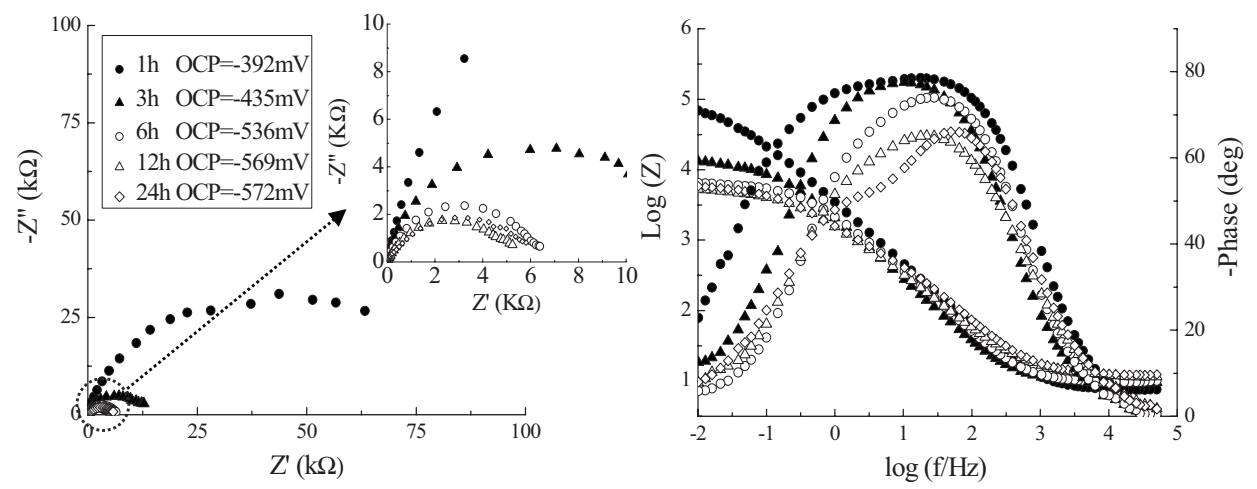

(a) Specimen CC
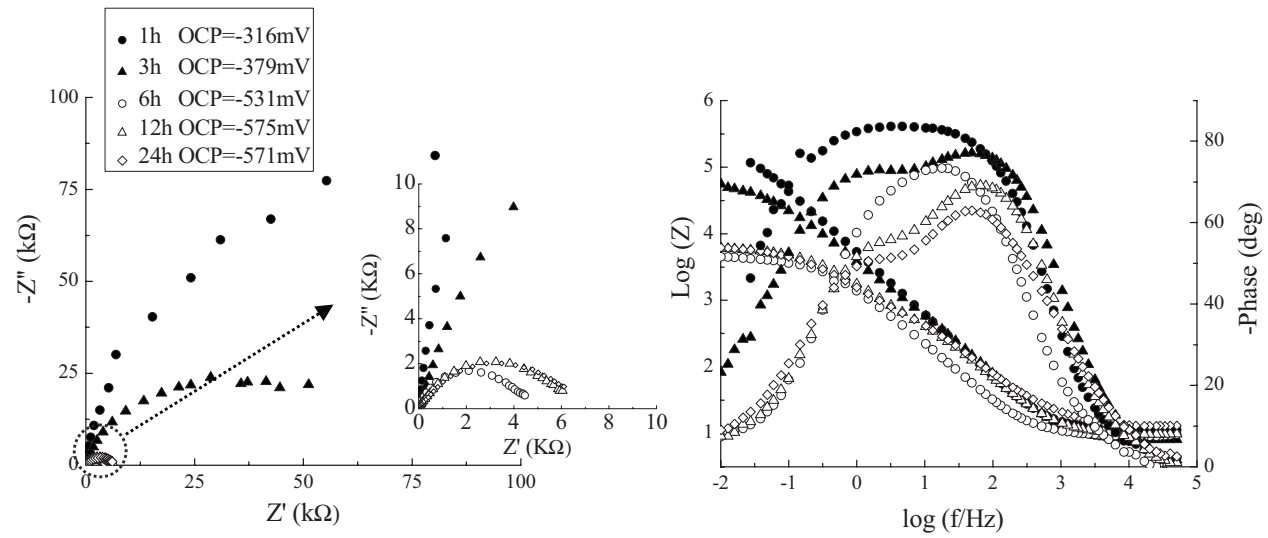

Figure 4. EIS response in Nyquist and Bode format for corroding specimens.

(b) Specimen $\mathrm{CNC}$

The experimental EIS response was fitted using an equivalent circuit, consisting of two time constants in series with the electrolyte resistance, $R_{\text {el }}\left(\left[Q_{c}\left[R_{c t}\left(Q_{r e d} R_{\text {red }}\right)\right]\right)\right.$. The summarized values for all cells and time intervals are given in Table I. In general, different equivalent electrical circuits [as well as both pure capacitances and/or constant phase elements (Q)] can be used for interpretation and data fitting of the experimental EIS response. Bearing in mind the duration of the tests, the addition of more time constants would

\begin{tabular}{|c|c|c|c|c|c|c|c|c|}
\hline $\begin{array}{l}\text { Time } \\
\text { interval }\end{array}$ & $\begin{array}{c}\mathrm{R}_{\mathrm{ct}} \\
\left(\mathrm{k} \Omega \mathrm{cm}^{2}\right)\end{array}$ & $\begin{array}{c}\mathrm{Q}_{\mathrm{pr} . \mathrm{l}}, \mathrm{Y}_{0} \\
\left(\times 10^{-5} \Omega^{-1} \mathrm{~s}^{\mathrm{n}}\right)\end{array}$ & $n$ & $\begin{array}{c}\mathrm{R}_{\mathrm{red}} \\
\left(\mathrm{k} \Omega \mathrm{cm}^{2}\right)\end{array}$ & $\begin{array}{c}\mathrm{Q}_{\text {red }}, \mathrm{Y}_{0} \\
\left(\times 10^{-5} \Omega^{-1} \mathrm{~s}^{\mathrm{n}}\right)\end{array}$ & $n$ & $\begin{array}{c}\mathrm{R}_{\mathrm{p}} \\
\left(\mathrm{k} \Omega \mathrm{cm}^{2}\right)\end{array}$ & $\begin{array}{c}\mathrm{R}_{\mathrm{p}} \\
{\left[\mathrm{k} \Omega \mathrm{cm}^{2}(\mathrm{PD})\right]}\end{array}$ \\
\hline \multicolumn{9}{|c|}{ Specimen C (control, micelles free) } \\
\hline $1 \mathrm{~h}$ & 1.90 & 4.02 & 0.8273 & 157.30 & 1.78 & 0.9441 & 159.20 & 186 \\
\hline $3 \mathrm{~h}$ & 2.89 & 3.42 & 0.8956 & 84.50 & 2.19 & 0.9663 & 87.39 & 158 \\
\hline $12 \mathrm{~h}$ & 0.43 & 8.76 & 0.9887 & 118.95 & 1.36 & 0.9069 & 119.38 & 128 \\
\hline $24 \mathrm{~h}$ & 0.59 & 2.58 & 0.8664 & 116.35 & 2.18 & 0.9114 & 116.94 & 182 \\
\hline \multicolumn{9}{|c|}{ Specimen CC (corroding, micelles free) } \\
\hline $1 \mathrm{~h}$ & 0.52 & 7.00 & 0.8567 & 43.55 & 5.74 & 0.8822 & 44.07 & 58 \\
\hline $3 \mathrm{~h}$ & 0.65 & 8.82 & 0.7934 & 5.20 & 4.62 & 0.9206 & 5.85 & 10 \\
\hline $6 \mathrm{~h}$ & 0.13 & 6.83 & 0.8755 & 1.60 & 8.25 & 0.8944 & 1.73 & 5 \\
\hline $12 \mathrm{~h}$ & 0.07 & 6.92 & 0.8018 & 1.95 & 2.62 & 0.7308 & 2.02 & 5 \\
\hline $24 \mathrm{~h}$ & 0.13 & 66.9 & 0.9871 & 3.64 & 1.01 & 0.7604 & 3.77 & 5 \\
\hline $1 \mathrm{~h}$ & 1.82 & 3.30 & 0.8782 & 130.65 & 2.56 & 0.9607 & 132.47 & 143 \\
\hline $3 \mathrm{~h}$ & 1.95 & 2.51 & 0.8667 & 68.90 & 2.73 & 0.9409 & 70.85 & 114 \\
\hline $6 \mathrm{~h}$ & 0.46 & 1.78 & 0.9989 & 88.15 & 1.48 & 0.9235 & 88.61 & 174 \\
\hline $12 \mathrm{~h}$ & 0.33 & 7.64 & 0.9899 & 99.45 & 1.17 & 0.8688 & 99.78 & 94 \\
\hline $24 \mathrm{~h}$ & 0.39 & 5.61 & 0.9919 & 76.70 & 1.16 & 0.8654 & 77.09 & 101 \\
\hline \multicolumn{9}{|c|}{ Specimen CNC (corroding, micelles containing) } \\
\hline $1 \mathrm{~h}$ & 1.24 & 2.76 & 0.8349 & 104.00 & 3.82 & 0.9989 & 105.24 & 114 \\
\hline $3 \mathrm{~h}$ & 0.83 & 4.29 & 0.8846 & 36.40 & 1.84 & 0.8823 & 37.23 & 33 \\
\hline $6 \mathrm{~h}$ & 0.15 & 4.37 & 0.8876 & 1.30 & 1.77 & 0.7761 & 1.45 & 4 \\
\hline $12 \mathrm{~h}$ & 0.26 & 6.64 & 0.9891 & 3.90 & 1.53 & 0.8096 & 4.16 & 5 \\
\hline $24 \mathrm{~h}$ & 0.15 & 9.69 & 0.9998 & 4.16 & 0.55 & 0.7131 & 4.31 & 5 \\
\hline
\end{tabular}



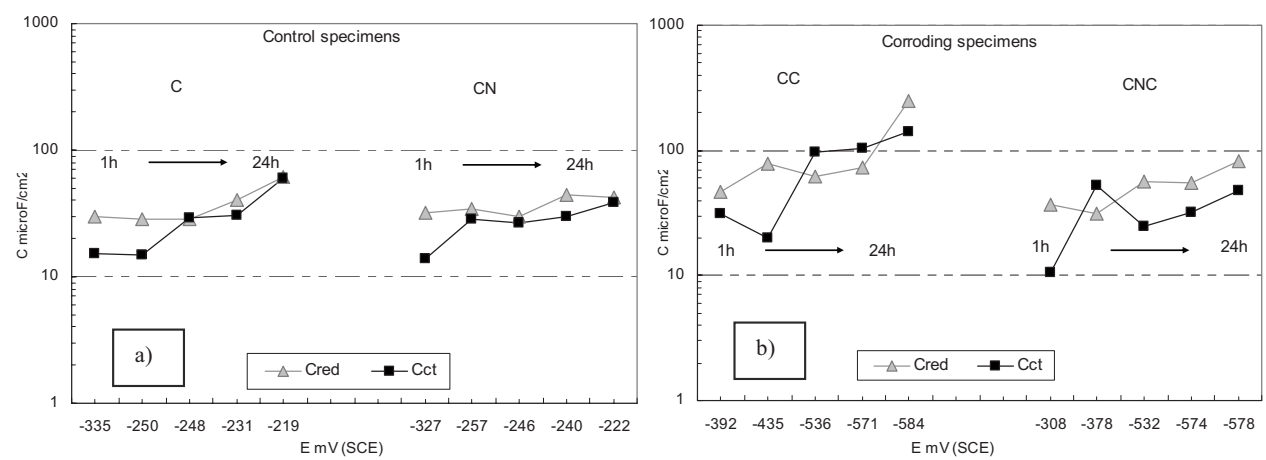

Figure 5. Evolution of $\mathrm{C}_{\mathrm{ct}}$ and $\mathrm{C}_{\text {red }}$ for (a) control cases $\mathrm{C}$ and $\mathrm{CN}$ and (b) corroding cases $\mathrm{CC}$ and $\mathrm{CNC}$. not add more clarity and accuracy in the results. Therefore, the hereby used circuit is considered to be sufficiently describing the behavior of the steel electrodes; moreover, a clear physical meaning can be thus ascribed to each parameter involved. The first time constant deals with the charge transfer resistance and pseudodouble layer capacitance $\left(\mathrm{R}_{\mathrm{ct}}\right.$ and $\mathrm{Q}_{\mathrm{ct}}$, respectively); the second time constant is related to redox transformations, mainly $\mathrm{Fe}^{2+} / \mathrm{Fe}^{3+}$, in the surface layers $\left(\mathrm{R}_{\text {red }}\right.$ and $\mathrm{Q}_{\text {red }}$, respectively). The replacement of pure capacitance $(\mathrm{C})$ with constant phase element (CPE or Q) in the equivalent circuits is widely accepted for systems as in this study, ${ }^{56-59}$ being denoted to inhomogeneities at different levels, hereby being mainly relevant to the heterogeneity of hydration/ corrosion products that form on the steel surface, in addition to the participation of micelles in the product layer formation. The CPE is an empirical mathematical description of the observed impedance response and is defined as ${ }^{52}: Z=(\mathrm{j} \omega)^{-\mathrm{n}} / Y_{0}$, being further quantified by the parameters $Y_{0}$ and $n$ (CPE constant and CPE factor, respectively), where $Y_{0}$ is a parameter with units $\Omega^{-1} \mathrm{~s}^{\mathrm{n}}$ and $0<n \leqslant 1$. When $n=1$ a CPE simplifies an ideal capacitor (when $n=0 \mathrm{CPE}$, simplifies a pure resistor); when $0<n<1$, characteristic is a nonideal capacitive response. The similarity between the impedance relations of a capacitor (C) and CPE makes it tempting to approximate $\mathrm{Q}$ as a capacitance when $n$ approaches 1 (as in this study, $n$ values for $\mathrm{C}$ and $\mathrm{CN}$ are in the range of 0.86-0.99), but this could be an inappropriate approximation; ${ }^{60} \mathrm{Q}$ does not have units of capacitance, and small deviations of the $n$ values from 1 can lead to large computational errors of capacitance. ${ }^{60-62}$ Therefore, using CPE (or $\mathrm{Q}$ ), instead of pure $\mathrm{C}$, was considered in the hereby used equivalent circuits (a thorough description of CPE behavior is provided, for example, in Refs. 63-67). In addition, in order to consider previously reported investigation for similar systems as the hereby investigated ones, ${ }^{45,46,54}$ the derived pseudocapacitance values were recalculated as pure capacitance [based on known relations of CPE and C, e.g., for a given frequency $\omega$, the following relation between the imaginary part of the impedance of the CPE $\left(Z_{\mathrm{CPE}}\right)$ and the impedance of the fitted capacitance $\left(Z_{\mathrm{C}}\right)$ is valid: $\operatorname{Im}\left(Z_{\mathrm{CPE}}\right)$ $=Z_{\mathrm{C}} \leftrightarrow \operatorname{Im}\left[1 / Y_{\mathrm{o}}\left(j \omega^{-n}\right]=1 / j \omega C\right] .{ }^{68} \mathrm{~A}$ comparison of $\mathrm{C}_{\mathrm{red}}$ and $\mathrm{C}_{\mathrm{ct}}$ for the investigated cases in relation to OCP values is given in Fig. 5.

The shape of the experimental curves for all specimens is reflecting typical response of steel in alkaline medium, simulating cement paste and in conditions of chloride present at the steel/paste interface. ${ }^{69-71}$ At low frequencies $(0.01 \mathrm{~Hz})$, a close to capacitive behavior was observed for specimens $\mathrm{C}$ and $\mathrm{CN}$ (control cases). In contrast, inclined to the real axis, semicircles are characteristic for specimens CC and CNC (corroding cases). The response for specimens $\mathrm{CC}$ and $\mathrm{CNC}$ reflects the evolution of corrosion with time, also evidenced by the more significant phase angle drop (from 80 to $\sim 60^{\circ}$ and lower) for these specimens, compared to the control ones $\mathrm{C}$ and $\mathrm{CN}$ (phase angle of $76-85^{\circ}$ ). The EIS results indicate that the micelles apparently alter the surface layer composition and result in an initial corrosion resistance improvement. Table I depicts the calculated global polarization resistance $\left(R_{p}\right)$ values derived by EIS (based on a well known, simplified calculation of $R_{p}=R_{c t}+R_{r e d}$ when the overall reaction rate and $R_{p}$, respectively, is also related to product layer transformations, including both oxidation and reduction, etc. ${ }^{72}$ ).

Figure 5 depicts a comparison of capacitance values $\left(\mathrm{C}_{\mathrm{ct}}\right.$ and $\mathrm{C}_{\mathrm{red}}$ ) for all cells at all time intervals. As can be observed, the values of $\mathrm{C}_{\mathrm{ct}}$ and $\mathrm{C}_{\mathrm{red}}$ for the control cells $\mathrm{C}$ and $\mathrm{CN}$ tend to be similar and at lower scale (OCP values between -210 and $-230 \mathrm{mV}$ vs SCE at the end of the test), compared to these for the corroding specimens $\mathrm{CC}$ and $\mathrm{CNC}$ (Fig. 5). The recorded evolution of $\mathrm{C}_{\mathrm{ct}}$ and $\mathrm{C}_{\mathrm{red}}$ at the corresponding OCP values accounts for the low rate of oxidation processes for specimens $\mathrm{C}$ and $\mathrm{CN}$ (indicating passivity). ${ }^{54} \mathrm{The}$ derived values and trends of capacitance change with treatment, also related to the OCP values, are consistent with the range of such, previously derived for model solutions ${ }^{46,54}$ and correspond well to the derived high resistance values $\left(R_{\text {red }}\right.$ and $\left.R_{c t}\right)$ in the range of $77-160 \mathrm{k} \Omega \mathrm{cm}^{2}$, denoting for the passive state of the steel electrodes (specimens $\mathrm{C}$ and $\mathrm{CN}$ ).

In contrast, for specimens $\mathrm{CC}$ and $\mathrm{CNC}$, significantly higher values for both $\mathrm{C}_{\mathrm{ct}}$ and $\mathrm{C}_{\text {red }}$ were recorded (Fig. 5b). For the former case (specimen $\mathrm{CC}$ ), the higher capacitance $\left(\mathrm{C}_{\mathrm{ct}}\right)$ values correspond to a lower resistance $\left[\mathrm{R}_{\mathrm{ct}}\right.$ in the range of $0.5 \mathrm{k} \Omega \mathrm{cm}^{2}$ ( $1 \mathrm{~h}$ response) to $0.13 \mathrm{k} \Omega \mathrm{cm}^{2}\left(24 \mathrm{~h}\right.$ response)]; the resistance $\left(\mathrm{R}_{\mathrm{ct}}\right)$ values for $\mathrm{CNC}$ are higher (well in line with lower $\mathrm{C}_{\mathrm{ct}}$ ), being in the range of $1.2 \mathrm{k} \Omega \mathrm{cm}^{2}$ (1 h response) to $0.15 \mathrm{k} \Omega \mathrm{cm}^{2}$ (24 h response).

The evolution of $R_{p}$ values derived from EIS present a similar trend to the $R_{p}$ values derived from PDP tests (although PDP presents the behavior of the steel electrodes with external polarization and therefore exactly the same $R_{p}$ value from both methods is not possible and consequently not recorded). The summarized $R_{p}$ values from PDP measurements are given in Table I, and the recorded behavior with external polarization is summarized in what follows. PDP.- The PDP curves for all investigated cases at the time intervals of 1, 3, 6, and $24 \mathrm{~h}$ are shown in Fig. 6 (6 and $12 \mathrm{~h}$ response being almost identical, therefore $12 \mathrm{~h}$ data are not presented).

As seen from Fig. 6, the specimens immersed in the chloride-free solutions (specimen $\mathrm{C}$ and $\mathrm{CN}$ ) depict similar behavior with external polarization (as also recorded by EIS): the corrosion potential is more anodic than $-270 \mathrm{mV}$, and the corrosion current density is low, meaning that the steel electrodes from both specimens $\mathrm{C}$ and $\mathrm{CN}$ are in passive state. For the specimens immersed in the chloridecontaining solutions (specimen $\mathrm{CC}$ and $\mathrm{CNC}$ ), the data showed a pronounced positive effect of the micelles at early stages (Figs. 6a $1 \mathrm{~h}$ and $6 \mathrm{~b} 3 \mathrm{~h}$ ), evidenced by a more anodic corrosion potential, lower corrosion, and anodic current densities for the micellescontaining specimen CNC (actually similar to the control specimens at $1 \mathrm{~h}$ time interval). Within continued treatment, there was no significant influence of the micelles (Fig. 6c $6 \mathrm{~h}$ and $6 \mathrm{~d} 24 \mathrm{~h}$ ). However, for the micelles-containing specimen $\mathrm{CNC}$, the corrosion potential remained slightly more anodic and the anodic current density slightly lower, compared to the micelles-free specimen CC.

As mentioned in the introduction part, the micelles used in this study do not belong to organic corrosion inhibitors (because the 

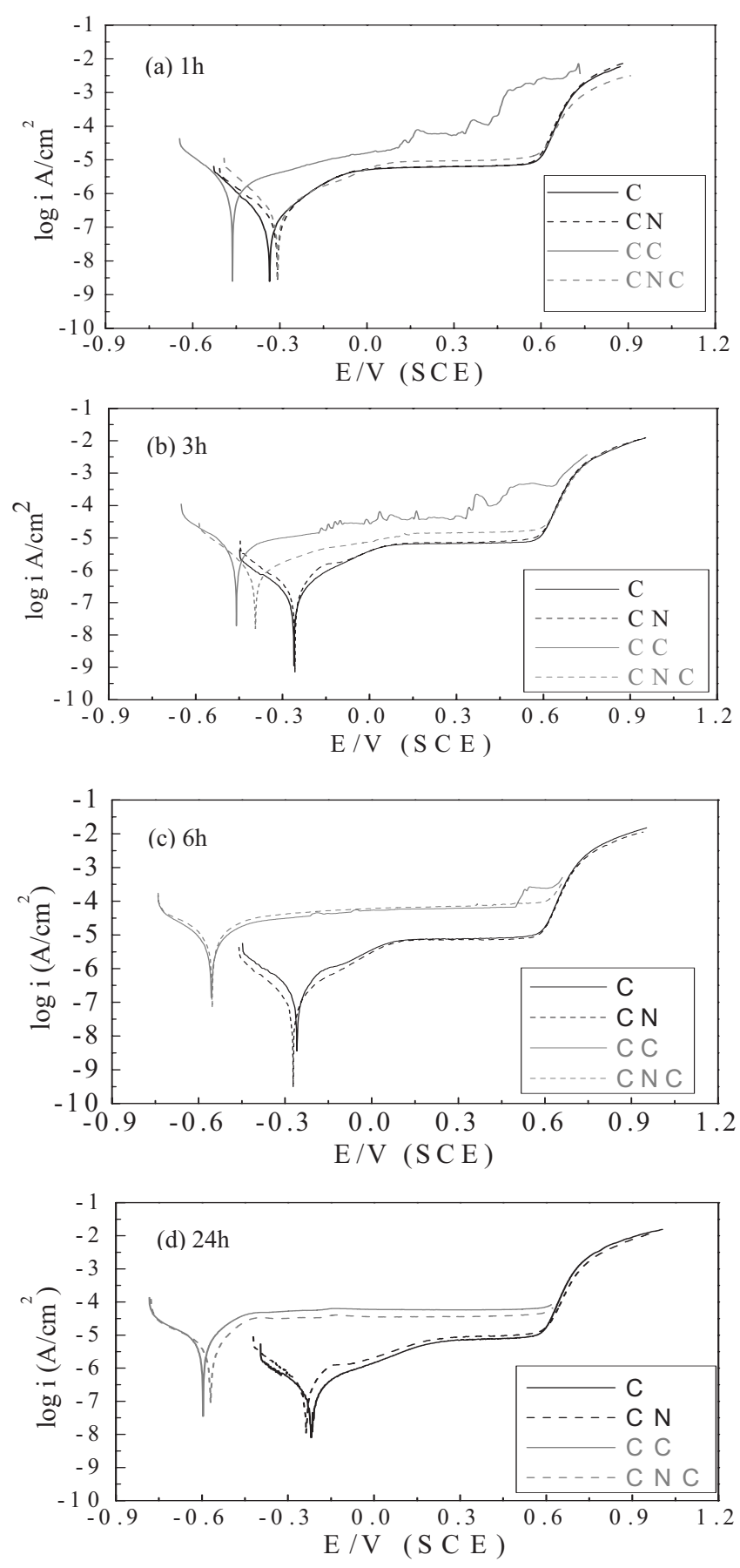

Figure 6. Potentiodynamic polarization of steel in CE at different time intervals.

previously synthesized and stabilized micelles are added to the model solutions, rather than adding organic compounds known to form micelles); however, some similar effects with regard to steel corrosion behavior can be observed. The PDP curves (Figs. 6a and 6b) show that, for the corroding specimens (before corrosion initiation), the presence of micelles reduced the anodic current by approximately 1 order of magnitude; on the other hand, their effect on the cathodic current was not obvious. The results indicate that the micelles mainly hinder the anodic reaction on the steel surface (due to the micelles absorption, which can impede chloride diffusion through the surface layer and delay steel corrosion), which is an effect (although for different environmental conditions) similar to the action of reported organic inhibitors of different composition and structure. $^{21,30,32}$ The summarized $\mathrm{R}_{\mathrm{p}}$ values, derived from potentiodynamic polarization, are shown in Table I. For the control specimens, the $R_{p}$ was quite high (in the range of $100-200 \mathrm{k} \Omega \mathrm{cm}^{2}$ ), which indicates passivity. For the corroding specimens, the same trend as within EIS measurements was observed: the $R_{p}$ value of the steel immersed in the micelles-containing solution was higher than that in the micelles-free solution at early stages, such as $1 \mathrm{~h}$ $\left(115 \mathrm{k} \Omega \mathrm{cm}^{2}\right.$ for the former, compared to $58 \mathrm{k} \Omega \mathrm{cm}^{2}$ for the latter case) and $3 \mathrm{~h}\left(33 \mathrm{k} \Omega \mathrm{cm}^{2}\right.$ for specimen CNC versus $10 \mathrm{k} \Omega \mathrm{cm}^{2}$ for specimen $C$ ). Further, similar $\mathrm{R}_{\mathrm{p}}$ values for both specimens $\mathrm{CC}$ and $\mathrm{CNC}$ were recorded at later stages. Based on the electrochemical measurements, it can be stated that the presence of micelles in the model solutions is able to increase the corrosion resistance of the steel electrodes; an obvious improvement, however, only appears at early stages, which is to a certain extent an expected outcome, considering the very low concentration of micelles in this study (of only 0.0024 wt \%).

Steel surface analysis.-Morphological observation and EDX analysis on the steel surface.- Figures 7 and 8 shows the morphology of the steel surface after treatment in cement extracts for 1 and $120 \mathrm{~h}$ (no significant difference between $1 \mathrm{~h}$ and earlier intervals as $3,6,12$, and $24 \mathrm{~h}$ was observed), respectively. The results from EDX analysis (most relevant elements) at $1 \mathrm{~h}$ time interval are summarized in Table II.

At early immersion stage $(1 \mathrm{~h})$, for the control specimens (Figs. $7 \mathrm{a}$ and $7 \mathrm{~b}$ ), similar morphology and composition (Table II) were recorded. For the corroding specimens (Figs. 7c and 7d), in addition to the well pronounced "pitting" corrosion (both for specimens CC and $\mathrm{CNC}$ ), micelles absorbed to the steel surface in specimen CNC can be observed at a higher magnification (Fig. 7d). The presence of micelles on the steel surface would be expected to improve at least the barrier properties of the formed layer; this effect, however, appeared to be relevant only at early immersion intervals as evidenced by the electrochemical response (Figs. 3-6). Within longer immersion times, there is no obvious difference in the appearance of the product layers as observed by ESEM (Fig. 8) except that the product layer for the micelles-containing specimen was visually more homogeneous and compact, which also corresponds to the similar corrosion behavior of the specimens at these stages.

The micelles, present in the solutions (both control and corroding cases $\mathrm{CN}$ and $\mathrm{CNC}$ ), exerted alterations in the product layer formation and composition on the steel surface. Although EDX analysis is a qualitative and semiquantitative technique, it can serve for comparative purposes and additional evidence: for example, based on the EDX results at $1 \mathrm{~h}$ time interval, more carbon was detected for the micelles-containing specimens (for control specimens $\mathrm{CN}$, the carbon content was $8.66 \mathrm{wt} \%$, compared to $6.83 \mathrm{wt} \%$ for the micelles-free specimen $\mathrm{C}$ ), indicating that the micelles were $\mathrm{ab}$ sorbed on the steel surface. In addition, the chloride concentration was lower for the micelles-containing corroding specimen CNC (2.11 wt \%), compared to specimen CC (3.13 wt \%), which would result in a layer with a better protective ability for specimen CNC. Further, steel surface analysis was performed by XPS, which will be discussed in what follows.

XPS. - The XPS analysis was performed on the steel surface of all investigated cases after treatment of $3 \mathrm{~h}$ (the time interval " $3 \mathrm{~h}$ " was chosen for XPS, because the difference in electrochemical behavior were most apparent at this stage). Table III presents the surface atomic concentration (atom \%) of the most relevant elements for all specimens.

XPS carbon $(C 1 s)$ ionizations. - Table IV presents the total carbon content on the surface of the investigated layers in comparison to a "control" case of the nanoaggregates ( $\mathrm{PEO}_{113}-\mathrm{b}-\mathrm{PS}_{70}$ micelles) only. The XPS measurement for micelles only was performed on a droplet of the as-received micelles solution on aerosil $\mathrm{SiO}_{2}$. Figure 9 depicts the detailed $\mathrm{C} 1 \mathrm{~s}$ spectrum for the micelles. As seen from Tables III and IV, specimens $\mathrm{CN}$ and $\mathrm{CNC}$ present higher amounts 

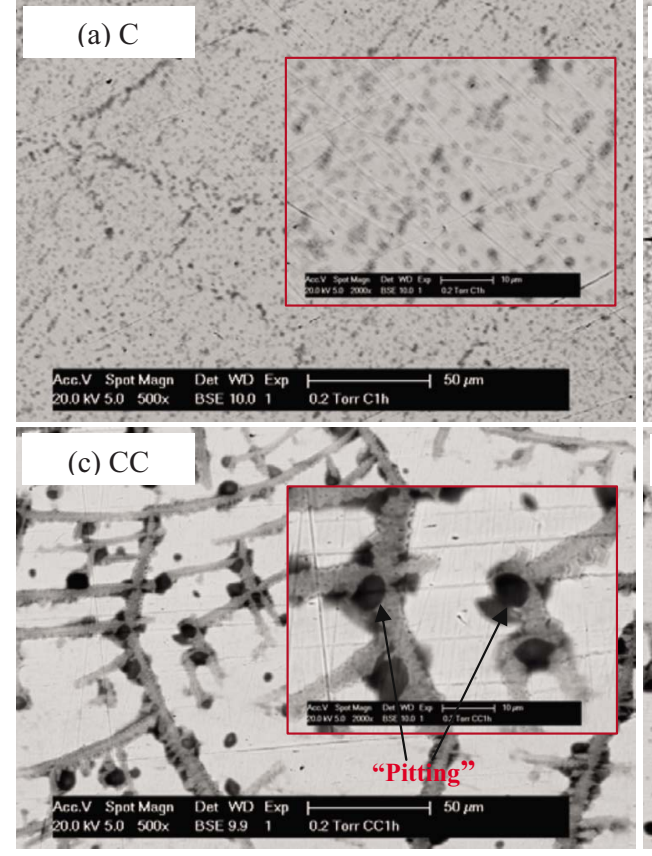
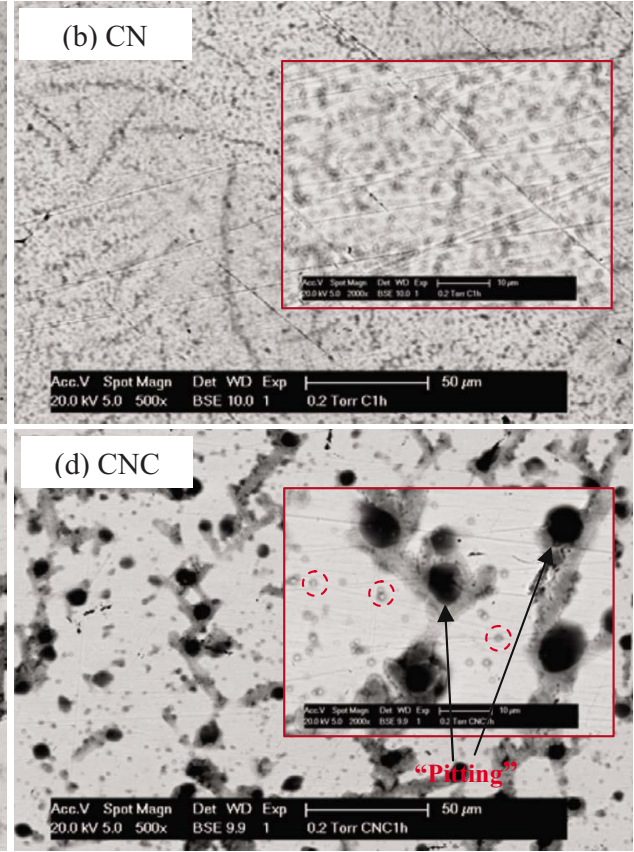

Figure 7. (Color online) Morphology of steel surface in CE solutions at $1 \mathrm{~h}$ obtained by ESEM. of carbon (also evident from the higher intensity of the $\mathrm{C} 1 \mathrm{~s} 285 \mathrm{eV}$ peaks, Fig. 10), compared to specimens $\mathrm{C}$ and CC. The fitting of the recorded XPS spectra was performed, using a symmetrical GaussLorentzian curve fitting after Shirley-type subtraction of the background and considering reported procedures. ${ }^{73,74}$ The relevant binding energy (BE) for the characteristic peaks after curve fitting (Figs. 9 and 10) and the corresponding bonds (including the percentage of the relevant peaks from the total carbon content) are given in Table IV [to be noted is that the C1s spectra (Fig. 10) include the relevant peaks for K, at binding energies higher than $292 \mathrm{eV}$, which will be further separately discussed].

The C1s spectra for the control (micelles only) sample and for specimens $\mathrm{CN}$ and $\mathrm{CNC}$ were decomposed into three components (Figs. 9 and 10b, Table IV): at $285 \mathrm{eV}$, corresponding to carbon only, bound to carbon and hydrogen $[\mathrm{C}-(\mathrm{C}-\mathrm{H})]$; near $286.5 \mathrm{eV}$, cor- responding to a single bond carbon-oxygen $(\mathrm{C}-\mathrm{O})$; and at 289.2-289.7 eV, due to a double bond carbon-oxygen $(\mathrm{O}-\mathrm{C}=\mathrm{O})$, which is denoted to $\mathrm{CO}_{3}^{2-}$ containing compounds. Similar curve fit of the $\mathrm{C} 1 \mathrm{~s}$ spectrum was applied for the "control" (micelle only sample), except that there is no peak between 289.2 and $289.7 \mathrm{eV}$, but the characteristic peak (shake up) for PS (the "core" of the micelles) appears at $291.5 \mathrm{eV}$ (Ref. 75) (Fig. 9, Table IV). The peak at about $286.5 \mathrm{eV}$ for the "control," micelle sample, including the shape of the C1s spectrum as a whole (Fig. 9), denotes for the PEO "part" (the "shell") of the micelles. ${ }^{76-78}$ In other words, the shape of the $\mathrm{C} 1 \mathrm{~s}$ spectrum for specimens $\mathrm{CN}$ and $\mathrm{CNC}$, including the characteristic binding energies (Table IV) and surface and shape of the peaks at about $286.5 \mathrm{eV}$ (Figs. 9 and 10), proves the presence of micelles ( $6 \%$ for specimen $\mathrm{CN}$ and $4 \%$ for specimen $\mathrm{CNC}$ ) in the
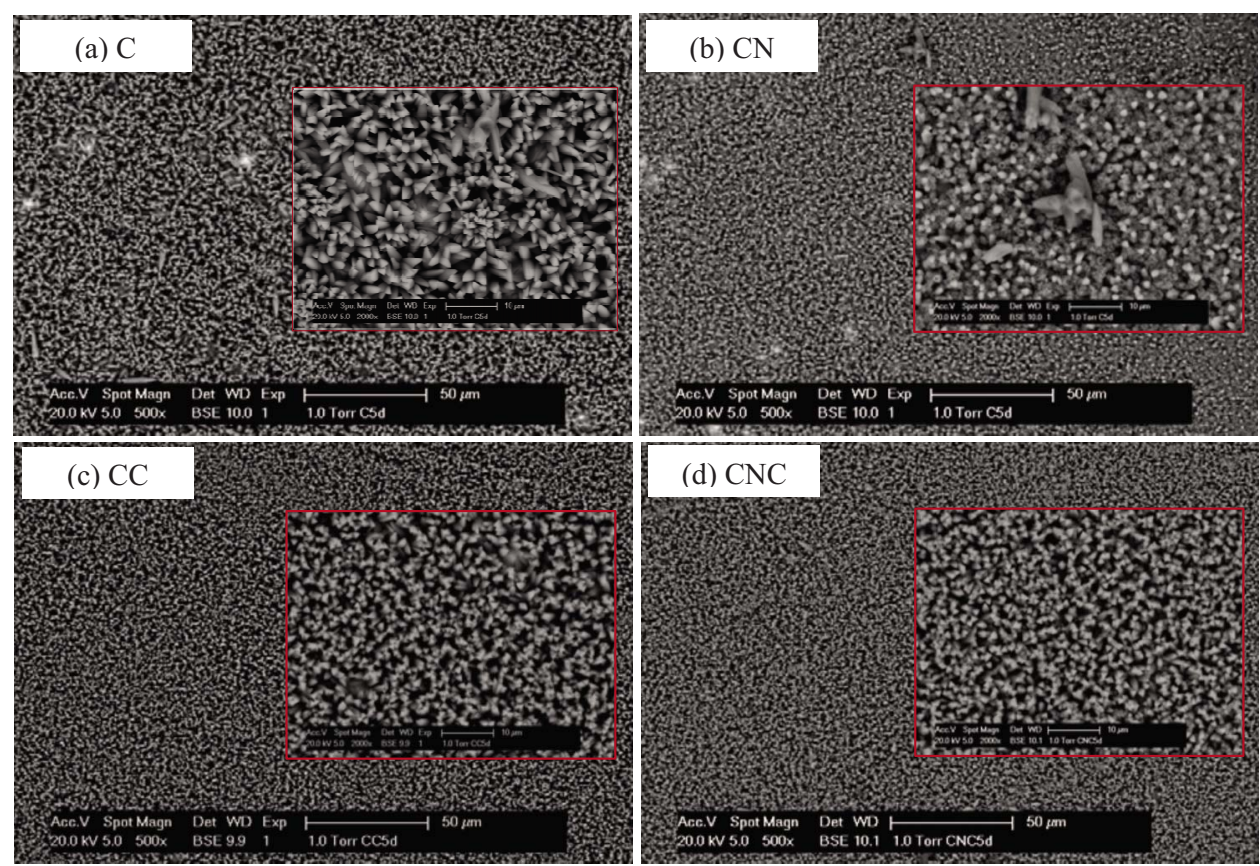

Figure 8. (Color online) Morphology of steel surface in CE solutions at $120 \mathrm{~h}$ obtained by ESEM. 


\begin{tabular}{|c|c|c|c|c|}
\hline Elements & $\mathrm{C}$ (wt \%) & $\mathrm{CN}(\mathrm{wt} \%)$ & $\mathrm{CC}(\mathrm{wt} \%)$ & $\mathrm{CNC}(\mathrm{wt} \%)$ \\
\hline $\mathrm{Na}$ & 2.27 & 2.26 & 8.76 & 8.23 \\
\hline $\mathrm{Al}$ & 0.25 & 0.35 & 0.29 & 0.23 \\
\hline $\mathrm{Si}$ & 0.21 & 0.41 & 0.33 & 0.22 \\
\hline $\mathrm{S}$ & 0.31 & 0.58 & 0.44 & 0.42 \\
\hline $\mathrm{Cl}$ & 0.37 & 0.37 & 3.13 & 2.11 \\
\hline K & 1.15 & 1.60 & 1.47 & 1.06 \\
\hline $\mathrm{Ca}$ & 0.32 & 0.53 & 0.33 & 0.31 \\
\hline $\mathrm{Fe}$ & 83.22 & 78.81 & 76.41 & 75.97 \\
\hline
\end{tabular}

layer, formed on the steel surface, whereas these features of the $\mathrm{C} 1 \mathrm{~s}$ spectra in specimens $\mathrm{C}$ and $\mathrm{CC}$ are not present (Fig. 10a).

XPS potassium ( $\mathrm{K}$ in $\mathrm{Cls}$ ) ionizations.- For the K2p spectra.The shape of the peak in specimen $\mathrm{C}$ differs from the rest of the specimens; it is curve fitted (not hereby presented) into two peaks with binding energies at 293.6 and $293 \mathrm{eV}$, denoted to $\mathrm{K}_{2} \mathrm{SO}_{4} / \mathrm{K}_{2} \mathrm{SO}_{3}$ at the higher energy (BE $169.1 \mathrm{eV}$ in the relevant S2p spectra) and $\mathrm{KCl}$ at the lower energy (BE $198.4 \mathrm{eV}$ in the $\mathrm{Cl} 2 \mathrm{p}$ spectrum, $\mathrm{S} 2 \mathrm{p}$ and $\mathrm{Cl} 2 \mathrm{p}$ spectrum not presented). The K2p spectrum for specimen $\mathrm{CN}$ denotes for $\mathrm{KCl}$ at $293 \mathrm{eV}(\mathrm{BE} 198.5 \mathrm{eV}$ in the relevant $\mathrm{Cl} 2 \mathrm{p}$ spectrum); whereas in specimens $\mathrm{CC}$ and $\mathrm{CNC}$, $\mathrm{K}_{2} \mathrm{SO}_{4}$ is only relevant at $293.6 \mathrm{eV}$ [characteristic peaks with $\mathrm{BE}$ of $169.1 \mathrm{eV}$ in the S2p spectrum (not presented) and $293.3 \mathrm{eV}$ in the $\mathrm{K} 2 \mathrm{p}$ spectrum].

XPS calcium (Ca2p) ionizations. - Considering the Ca2p spectra (not presented) and the already discussed C1s spectra (Fig. 10), including the O1s ones (Fig. 11b), the following compounds are relevant: for specimen $\mathrm{C}: \mathrm{Ca}(\mathrm{CO})_{3}$, corresponding to binding energy $347.4 \mathrm{eV}$ (75\% of the total Ca content), and $\mathrm{CaO} / \mathrm{Ca}(\mathrm{OH})_{2}$, corresponding to binding energy $346.7 \mathrm{eV}$ ( $25 \%$ of the Ca content). For specimen $\mathrm{CN}: \mathrm{Ca}(\mathrm{CO})_{3}$ at binding energy $347.2 \mathrm{eV}(76 \%$ from the $\mathrm{Ca}$ content) and $\mathrm{CaO} / \mathrm{Ca}(\mathrm{OH})_{2}$ at $346.6 \mathrm{eV}$ (at $24 \%$ from the total $\mathrm{Ca}$ content). For the specimens $\mathrm{CC}$ and $\mathrm{CNC}$ (corroding surfaces), only $\mathrm{Ca}(\mathrm{CO})_{3}$ is relevant, corresponding to $347.4 \mathrm{eV}$ in the $\mathrm{Ca} 2 \mathrm{p}$ spectra and 289.5 and $289.7 \mathrm{eV}$ in the $\mathrm{C} 1 \mathrm{~s}$ spectra, respectively.

XPS oxygen $(\mathrm{Ols})$ and iron $(\mathrm{Fe} 2 \mathrm{p})$ ionizations.- Figure 11 presents the $\mathrm{Fe} 2 \mathrm{p}$ and $\mathrm{O} 1 \mathrm{~s}$ spectra for all specimens. When complex surface layers are investigated by XPS, the interpretation of the O1s

\section{C1s PEO-b-PS}

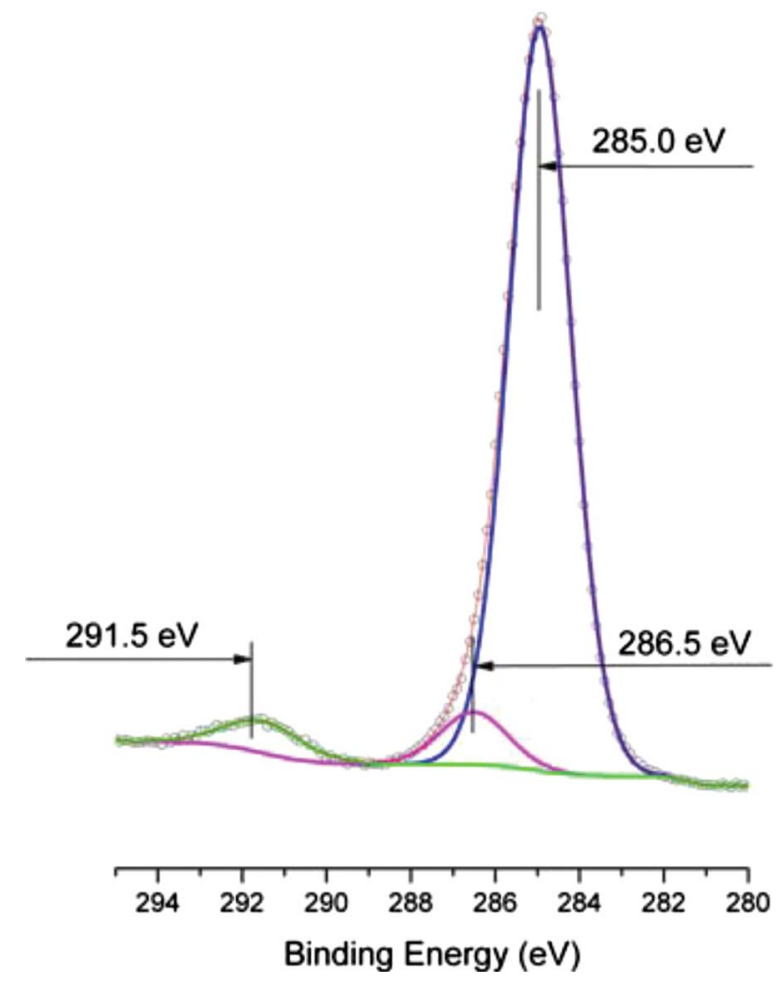

Figure 9. (Color online) Detailed C1s spectra for the "control" micelle only sample.

spectra is not always straightforward and is a complicated one. In the hereby discussed case, the surface layers contain a mixture of iron oxides/hydroxides, polymer nanoaggregates, oxides/hydroxides of alkaline metals (from the environmental medium, CE), carbonation, etc. Therefore, a simplified curve fitting, including only the main features of the $\mathrm{O} 1 \mathrm{~s}$ spectra (and the relevant differences between the investigated samples) is considered more appropriate and

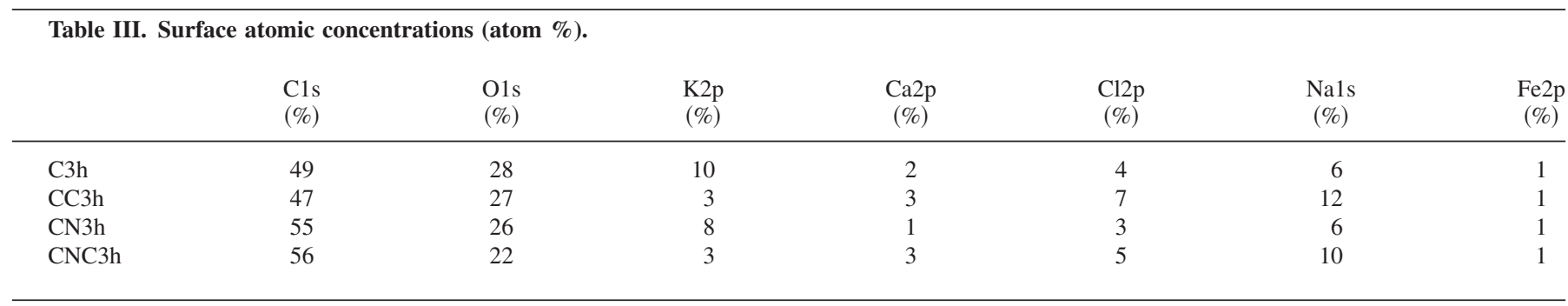

Table IV. Surface atomic concentrations C1s (atom \%).

\begin{tabular}{lccccc} 
BE & CC3h & C3h & CN3h & CNC3h & PEO-b-PS (control) \\
\hline $285 \mathrm{eV}$ & 40 & 42 & 47 & 48 & 57 \\
$(\mathrm{C}-\mathrm{C} / \mathrm{C}-\mathrm{H})$ & - & - & 6 & 4 & 5 \\
$286.5 \mathrm{eV}-286.6 \mathrm{eV}$ & 7 & 7 & 2 & 4 & - \\
$(\mathrm{C}-\mathrm{O})$ in C-H-O (PEO) & - & - & - & - & 3 \\
$289.2-289.7 \mathrm{eV}$ & $\mathrm{O}-\mathrm{C}=\mathrm{O})$ & 49 & 55 & 56 & 65 \\
$291.5 \mathrm{eV}$ & 47 & $\mathrm{O}$ in C-H-O (PS) & $\mathrm{C}$ & &
\end{tabular}


C1s

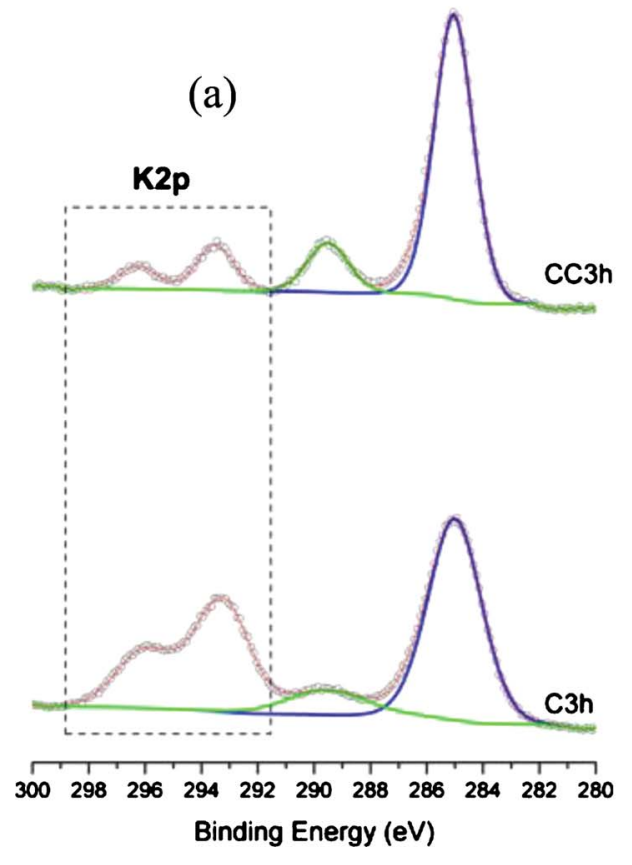

C1s

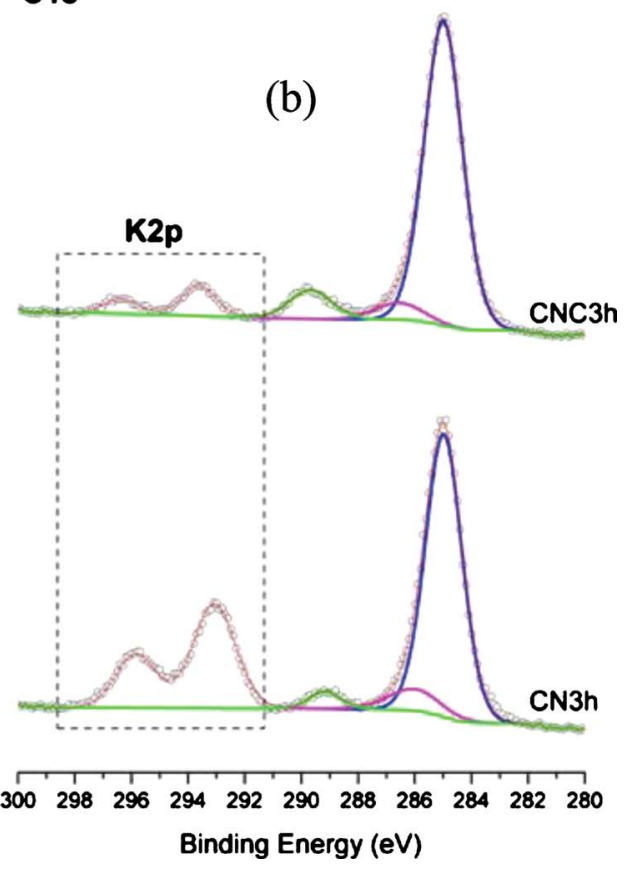

Figure 10. (Color online) $\mathrm{C}$ s spectra for (a) $\mathrm{C}$ and $\mathrm{CC}$ and (b) $\mathrm{CN}$ and CNC. reliable, rather then involving exact values and complicated interpretations. Further, the characteristic feature in the O1s spectra are correlated to the Fe2p spectra.

The $\mathrm{Fe} 2 \mathrm{p}$ line shape in iron oxides is similarly very complex, and the chemical shift between $\mathrm{Fe}^{2+}$ and $\mathrm{Fe}^{3+}$ components is too small to be exactly resolved within the energy resolution of the XPS measurements $(1 \mathrm{eV})$. Moreover, the percentage of iron/iron oxides on the surface of the investigated specimens is rather low [meaning accumulation of surface layers during treatment, mainly carbonates for the case of specimens $\mathrm{C}$ and $\mathrm{CC}$ and additionally, a surface, at least partially "blocked" from micelles (evident form the lower oxygen levels) in the specimens $\mathrm{CN}$ and CNC (Table III)]. However, certain features in the $\mathrm{Fe} 2 \mathrm{p}$ ionizations allow the identification of Fe-oxidation states and the relative compounds, the most reliable evidence being the satellite structures due to charge transfer screening ${ }^{79,80}$ and the overall shape of the spectrum for each investigated condition. Combined with the curve fitted O1s spectra, the difference in composition of the product layers can be clearly observed.
Fe2p

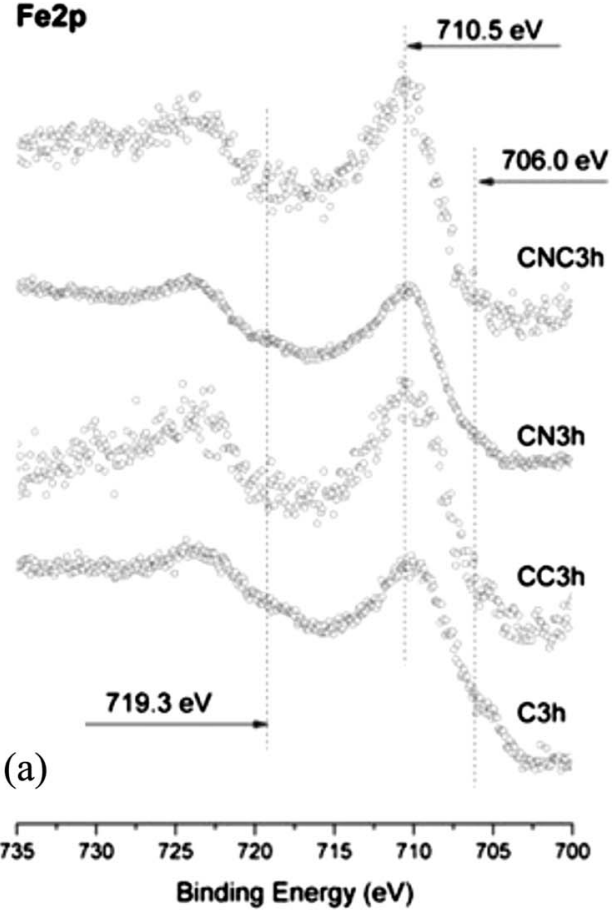

01s

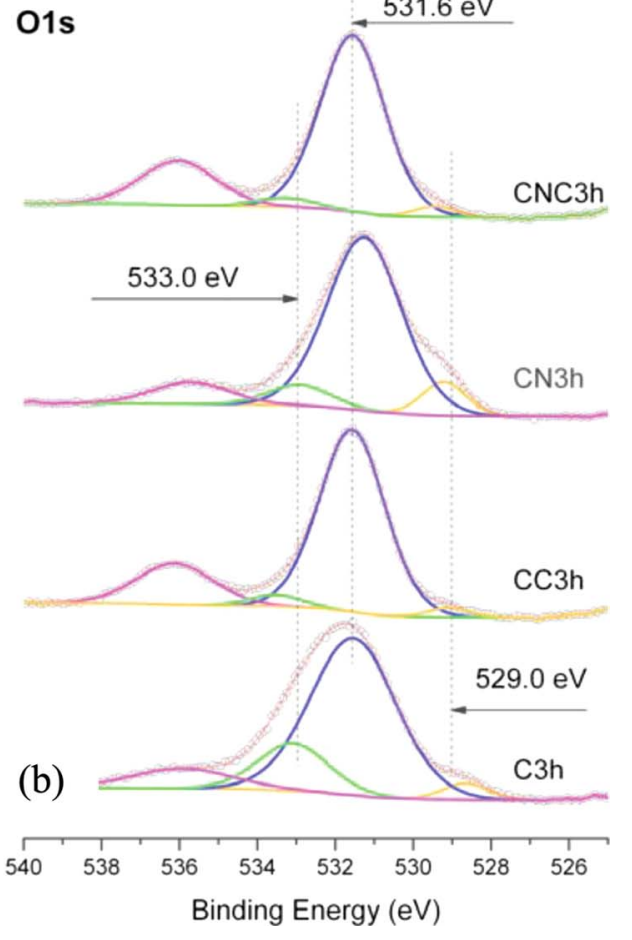

Figure 11. (Color online) (a) Fe2p and (b) O1s spectra for all specimens. 
Specimens $C$ and $C N$ (control specimens without and with micelles).- For specimen $\mathrm{C}$, the $\mathrm{Fe} 2 \mathrm{p}$ photoelectron peaks at 710 , 719 , and $723.6 \mathrm{eV}$ (Fig. 11a) represent binding energies of $2 \mathrm{p} 3 / 2$, shake-up satellite $2 \mathrm{p} 3 / 2$ and $2 \mathrm{p} 1 / 2$, respectively. The characteristic binding energies, the satellite at $719 \mathrm{eV}$, and the overall shape of the $\mathrm{Fe} 2 \mathrm{p}$ pattern for specimen $\mathrm{C}$ can be attributed to either $\mathrm{FeOOH}$ or $\mathrm{Fe}_{2} \mathrm{O}_{3}$, which are known to exhibit similar features and peak positions. The O1s pattern for specimen C, Fig. 11b, (as well as for specimen $\mathrm{CN}$ ) is decomposed into three peaks: at 528.7, 531.6, and $533.2 \mathrm{eV}$ corresponding to $\mathrm{O}_{2}^{-}, \mathrm{OH}^{-}$, and chemically or physically adsorbed water, respectively. The existence of surface $\mathrm{OH}^{-}$groups (5\% from the total O1s peak) suggests that the oxidized iron is likely in the state of $\mathrm{FeOOH}$. If the surface structure was $\mathrm{Fe}_{2} \mathrm{O}_{3}$, a single peak at $530 \mathrm{eV}$ should have been observed. ${ }^{81,82}$ Additional evidence for the most probable existence of $\mathrm{FeOOH}$ is the broadening of the $\mathrm{O} 1 \mathrm{~s}$ at lower binding energies (the peak at $528.7 \mathrm{eV}, 1 \%$ from the total O1s peak), which actually corresponds to $\mathrm{FeOOH} .{ }^{81,83,84}$

For specimen $\mathrm{CN}$, the $\mathrm{Fe} 2 \mathrm{p}$ photoelectron peaks at 710.3 and $724 \mathrm{eV}$ represent binding energies of $2 \mathrm{p} 3 / 2$ and $2 \mathrm{p} 1 / 2$, respectively; in contrast to specimen $\mathrm{C}$, the satellite at $719 \mathrm{eV}$ is less pronounced, and a plateau region is rather observed between 715 and $720 \mathrm{eV}$. In addition, there is a broadening of the $2 \mathrm{p} 1 / 2$ peak toward lower energy (at $722.3 \mathrm{eV}$ ). Consequently, the shape and characteristic features of the $\mathrm{Fe} 2 \mathrm{p}$ spectra for specimens $\mathrm{CN}$ denote for $\mathrm{Fe}_{3} \mathrm{O}_{4}$, present in the surface layer. ${ }^{73,85}$ Considering the features of the $\mathrm{O} 1 \mathrm{~s}$ spectrum for specimen $\mathrm{CN}$ (Fig. 11b), as an evidence for the presence of $\mathrm{Fe}_{3} \mathrm{O}_{4}$ in specimen $\mathrm{CN}$, the following is relevant: the $529.4 \mathrm{eV}$ peak (characteristic energy for $\mathrm{Fe}_{3} \mathrm{O}_{4}$ ), is $2.4 \%$ from the total oxygen on the surface and the significantly lower amount of adsorbed water (less $\mathrm{OH}$, evidenced by the $2.4 \%$ for the $533.2 \mathrm{eV}$ peak from the total O1s). Therefore, for specimen $\mathrm{CN}, \mathrm{Fe}_{3} \mathrm{O}_{4}$ is characteristic for the product layer on the steel surface.

Specimens CC and CNC (corroding specimens without and with micelles).- The photoelectron peaks at $710.5 \mathrm{eV}$ (CC) and $710.8 \mathrm{eV}$ (CNC) represent $\mathrm{Fe} 2 \mathrm{p} 3 / 2$; there is a broadening at $713.5 \mathrm{eV}$ and an additional broadening $(\mathrm{Fe} 2 \mathrm{p} 1 / 2)$ at $724-724.5 \mathrm{eV}$ and at $730 \mathrm{eV}$, respectively. These features and the shape of the $\mathrm{Fe} 2 \mathrm{p}$ spectrum for both $\mathrm{CC}$ and $\mathrm{CNC}$ specimens denote for the presence of $\mathrm{FeCO}_{3} .{ }^{86}$ The existence of the latter is also evidenced by the $289.2-289.5 \mathrm{eV}$ peaks in the $\mathrm{C} 1 \mathrm{~s}$ spectra (previously discussed, Fig. 10). Further, the shape of the $\mathrm{Fe} 2 \mathrm{p}$ for $\mathrm{CC}$, the $2 \mathrm{p} 3 / 2$ satellite at $719 \mathrm{eV}$, and the relatively high intensity of the $2 \mathrm{p} 1 / 2$ peak at $724 \mathrm{eV}$ (Fig. 11a, compared to specimen CNC) denote for the presence of $\mathrm{Fe}_{3} \mathrm{O}_{4}$ (most likely a mixture of $\mathrm{FeO}$ and $\mathrm{Fe}_{2} \mathrm{O}_{3}$ ). Evidence is also the lower energy peak in the O1s spectrum (Fig. 11b) at $529.1 \mathrm{eV}$ (corresponding to $\mathrm{Fe}_{3} \mathrm{O}_{4}$ ). The presence of $\mathrm{FeOOH}$ is not likely, because the $533.5 \mathrm{eV}$ peak in the $\mathrm{O} 1 \mathrm{~s}$ spectrum represents only $1.5 \%$ from the total $\mathrm{O} 1 \mathrm{~s}$, the higher energy broadening of the $\mathrm{O} 1 \mathrm{~s}$ peak is not as evident as in specimen $\mathrm{C}$ for example.

For specimen $\mathrm{CNC}$, along with the presence of $\mathrm{FeCO}_{3}$, the shape of the Fe2p (Fig. 11a) reveals the presence of $\alpha-\mathrm{Fe}_{2} \mathrm{O}_{3}$, evidenced by the following characteristic features: $2 \mathrm{p} 3 / 2$ peak at $710.8 \mathrm{eV}$, $2 \mathrm{p} 3 / 2$ shake-up at $719 \mathrm{eV}$, and a well pronounced $2 \mathrm{p} 1 / 2$ peak at $724 \mathrm{eV}$; additionally, the $\mathrm{Fe} 2 \mathrm{p} 3 / 2 \mathrm{fwhm}$ is $3.6 \mathrm{eV}$ (Ref. 56): all these features in $\mathrm{Fe} 2 \mathrm{p}$ denote for the presence of $\alpha-\mathrm{Fe}_{2} \mathrm{O}_{3}$ in the surface layer of specimen CNC. Additional evidence is the $529.8 \mathrm{eV}$ peak in the O1s spectrum (about $1 \%$ of the total O1s, denoted to $\mathrm{Fe}_{2} \mathrm{O}_{3}$ ). Further, compared to all other specimens, the peak at $533.2 \mathrm{eV}$ (denoted to hydroxides) is almost negligible, contributing with less than $1 \%$ in the total $\mathrm{O} 1 \mathrm{~s}$.

The morphology observation and surface analysis (Figs. 7d and 10b) reveal that similar to organic inhibitors, the micelles were absorbed on the steel surface. The absorbed micelles are expected to increase the "barrier effect" of the layer, delaying the breakdown of the passive film, which is a phenomenon generally known to be responsible for corrosion delay in the presence of organic inhibitors. ${ }^{32}$ Moreover, the XPS results (Fig. 11) indicate that the micelles can also alter the chemical compositions of the product layers: the product layers in the micelles-containing specimens $\mathrm{CN}$ and CNC present mainly protective $\alpha-\mathrm{Fe}_{2} \mathrm{O}_{3}$ and/or $\mathrm{Fe}_{3} \mathrm{O}_{4}$, leading to an impeded $\mathrm{Cl}^{-}$penetration and consequently corrosion delay; in contrast, the product layers in the micelles-free specimen $\mathrm{C}$ and $\mathrm{CC}$ were more hydrated, exhibiting mainly $\mathrm{FeOOH}, \mathrm{FeO}$, and $\mathrm{FeCO}_{3}$, which are prone to chloride attack. ${ }^{87,88}$

Correlation product layers composition/EIS parameters.- The XPS results (supported by ESEM and EDX) indicate that different types of iron oxide/hydroxide layers were formed on the steel surface after treatment in the test solutions with and without the presence of micelles. Further, a Ca-rich outer layer was formed (Figs. 7 and 8), which can additionally protect the steel. However, it is reported that the Ca-rich layer provides only limited protection and the inner layer of iron oxide/hydroxides is predominant to protect the steel. $^{54}$

The electrochemical response (and in particular the EIS parameters, Table I, Fig. 5) support the findings for product layers composition and the above discussed peculiarities of these layers, formed in each relevant condition. For the control groups, a lower charge transfer resistance $\mathrm{R}_{\mathrm{ct}}$ and a lower $\mathrm{R}_{\text {red }}$ were recorded for the micelle-containing specimens $(\mathrm{CN})$, compared to the micelle-free specimens $\mathrm{C}$ [both $\mathrm{C}$ and $\mathrm{CN}$ are passive steel, with certainly different (higher) scale of $\mathrm{R}_{\mathrm{p}}$ values, compared to $\mathrm{CC}$ and $\mathrm{CNC}$, Table $I]$. The lower $R_{c t}, R_{\text {red }}$, and $R_{p}$, respectively, for specimens $C N$ is hereby denoted to the less oxidized steel surface (Table III, also resulting from at least partial "blocking" of the surface from the micelles), and therefore a stable passive layer is apparently taking more time to form. In addition, considering that the electrical conductivity of $\mathrm{FeOOH}, \mathrm{Fe}_{2} \mathrm{O}_{3}$ and $\mathrm{Fe}_{3} \mathrm{O}_{4}$ is decreasing in the order: $\mathrm{Fe}_{3} \mathrm{O}_{4}>\mathrm{Fe}_{2} \mathrm{O}_{3}>\mathrm{FeOOH},{ }^{89}$ the product layer in specimens $\mathrm{C}$, being predominantly $\mathrm{FeOOH}$ is less conductive, i.e., higher diffusion limitations within $\mathrm{R}_{\mathrm{p}}$ measurements are relevant. In contrast, the product layer in specimens $\mathrm{CN}$ is mainly $\mathrm{Fe}_{3} \mathrm{O}_{4}$, thus a higher electrical and ionic conductivity would be expected, resulting in a lower (compared to specimen $C$ ) global $R_{p}$ values for the time interval of this test.

For corroding groups, the charge transfer resistance $\left(\mathrm{R}_{\mathrm{ct}}\right)$ for the specimen $\mathrm{CNC}$ is slightly higher, compared to the specimen CC; the $\mathrm{R}_{\text {red }}$ is significantly higher for 1 and $3 \mathrm{~h}$ and still higher for 12 and $24 \mathrm{~h}$ (Table I). The results indicate that the expected improvement of corrosion resistance in the corroding, micelles-containing specimens $\mathrm{CNC}$ is only significant at early time intervals, e.g., 1 and $3 \mathrm{~h}$, which is related to the compositions of the product layer formed on the steel surface.

As seen from Table III, the product layers in specimens $\mathrm{CN}$ and $\mathrm{CNC}$ (the micelles-containing specimens) present less oxygen, the lowest oxygen content being in specimen CNC $(\sim 22 \%)$. The XPS analysis reveals that micelles were apparently presented in the product layers (considering the features of the $\mathrm{C} 1 \mathrm{~s}$ spectra), also evidenced by ESEM and EDX (Fig. 8). Therefore, the presence of only $0.0024 \mathrm{wt} \%$ micelles in CE leads to increased barrier effects (at least on earlier stages) but also results in "blocking" the steel surface and less oxygen content.

Comparing the electrochemical response and surface layer properties of control and corroding specimens, the following is relevant: the product layers for specimens $\mathrm{C}$ and $\mathrm{CC}$ (both micelles-free) present $\mathrm{FeOOH}$ (for specimen $\mathrm{C}$ ) and a mixture of $\mathrm{FeCO}_{3}, \mathrm{FeO}$ and $\mathrm{Fe}_{2} \mathrm{O}_{3}$ (for specimen CC). Specimen $\mathrm{C}$ is a noncorroding specimen, where apparently the product layer was largely hydrated (because after treatment and within the XPS analysis, water is still present in the film). Specimen CC is a corroding specimen, where similar composition to specimen $\mathrm{C}$ would be expected before corrosion initiation. Because specimen $\mathrm{CC}$ was treated in $\mathrm{Cl}$-containing cement extract, logically the composition of the film changes (within corrosion initiation and propagation): chlorides are known to change the composition, thickness, and density of the passive films. ${ }^{90-92}$ The incorporation of water in the product layer will result in a more hydrated film with a decreased protective nature and ability because 
the water "paths" would facilitate chloride penetration and consequently will ease breakdown of the passive film. ${ }^{87,88}$ Therefore, an initially more hydrated film (as in CC) along with an easier $\mathrm{Cl}$ penetration, results in faster corrosion initiation and propagation. In contrast, a more dehydrated film, as would be in specimens $\mathrm{CN}$ and initially in specimens CNC (micelle containing) would be less prone to chloride attack, which in addition to the partially "blocked" by micelles steel surface (e.g., Figs. 7d and 10b), will result in an impeded $\mathrm{Cl}^{-}$penetration and consequently corrosion delay. These latter mechanisms are actually evidenced by the lower chloride content in the surface layer of corroding specimens CNC, compared to corroding specimens CC (Tables II and III), which in turn means better properties for $\mathrm{CNC}$ from a corrosion view point.

\section{Conclusions}

A preliminary study on the corrosion behavior of low carbon steel in cement extract (simulated pore solution) in the presence of polymeric nanoaggregates $\left(\mathrm{PEO}_{113}\right.$-b-PS $\mathrm{PS}_{70}$ micelles) is reported in this work. The electrochemical measurements indicate that a very low concentration of the micelles $(0.0024 \mathrm{wt} \%)$ is able to increase the corrosion resistance of the steel in the chloride-containing cement extract However, the significant effect only appears at early stages, which is to some extent as expected, considering the very low concentration of micelles used in this study.

The morphological observation and surface analysis confirm that the micelles are absorbed on the steel surface and would be expected to result in a more uniform and compact layer, i.e., to increase barrier properties. The XPS analysis reveals that the product layers of the micelles-containing specimens exhibit a more homogeneous and protective $\alpha-\mathrm{Fe}_{2} \mathrm{O}_{3}$ and/or $\mathrm{Fe}_{3} \mathrm{O}_{4}$, whereas the product layers of the micelles-free specimens exhibit more hydrated $\mathrm{FeOOH}, \mathrm{FeO}$, and $\mathrm{FeCO}_{3}$, which is prone to chloride attack. Therefore, the "barrier effect" along with the composition of the product layers on the steel surface (in addition to the very low concentration of the micelles) denote for the initially increased corrosion resistance of the steel in the chloride-containing cement extract in the presence of micelles.

Delft University of Technology assisted in meeting the publication costs of this article.

\section{References}

1. Corrosion of Reinforcement in Concrete, C. L. Page, K. W. J. Treadaway, and P. B. Bamforth, Editors, Elsevier Applied Science, London (1990).

2. Corrosion of Steel in Concrete, N. S. Berke, V. Chaker, and D. Whiting, Editors, ASTM STP 1065, ASTM, Philadelphia, PA (1990)

3. S. D. Cramer, B. S. Covino, S. J. Bullanrd, G. R. Holcomb, J. H. Russell, M. Zimolek-moroz, Y. P. Voramo, J. T. Bulter, F. J. Nelson, and N. G. Thompson, ISIJ Int., 42, 1376 (2002).

4. M. Pourbaix, Atlas of Electrochemical Equilibria in Aqueous Solutions, NACECEBELCOR, Houston, TX (1974).

5. G. Sahoo and R. Balasubramaniam, Corros. Sci., 50, 131 (2008).

6. L. J. Parrot, A Review of Carbonation in Reinforced Concrete, British Cement Association Report C/i-0987, London (1987).

7. A. Nasser, A. Clément, S. Laurens, and A. Castel, Corros. Sci., 52, 2878 (2010).

8. D. Beckett, Concrete, 1983, 16

9. M. M. Mennucci, E. P. Banczek, P. R. P. Rodrigues, and I. Costa, Cem. Concr. Compos., 31, 418 (2009).

10. B. Elsener, Corrosion Inhibitors for Steel in Concrete-State of the Art Report, EFC Publications, Number 35, Institute of Material, London (2001).

11. L. Dhouibi, E. Triki, and A. Raharinaivo, Cem. Concr. Compos., 24, 35 (2002).

12. O. Trocónis de Rincón, O. Pérez, E. Paredes, Y. Caldera, C. Urdaneta, and I. Sandoval, Cem. Concr. Compos., 24, 139 (2002).

13. H. Liang, L. Li, N. D. Poor, and A. Sagüés, Cem. Concr. Res., 33, 139 (2003).

14. R. Cigna, G. Familiari, F. Gianetti, and E. Proverbio, in Corrosion and Corrosion Protection of Steel in Concrete, R. N. Swamy, Editor, p. 878, Sheffield, United Kingdom (1994).

15. U. Mäder, Concrete, 9, 215 (1999).

16. J. M. Gaidis, Cem. Concr. Compos., 26, 181 (2004).

17. D. Bjegovic and B. Miksic, Mater. Perform., 11, 52 (1999)

18. F. Wombacher, U. Maeder, and B. Marazzani, Cem. Concr. Compos., 26, 209 (2004).

19. B. Elsener, M. Büchler, F. Stalder, and H. Böhni, Corrosion, 55, 1155 (1999)

20. M. Ormellese, M. Berra, F. Bolzoni, and T. Pastore, Cem. Concr. Res., 36, 536 (2006).

21. C. K. Nmai, S. A. Farrington, and G. S. Bobrowsky, Concr. Int., 14, 45 (1992).

22. H. E. Jamil, A. Shriri, R. Boulif, C. Bastos, M. F. Montemor, and M. G. S. Ferreira, Electrochim. Acta, 49, 2753 (2004).
23. L. Bertolini, B. Elsener, P. Pedeferri, and R. Polder, Corrosion of Steel in Concrete: Prevention, Diagnosis, Repair, 1st ed., John Wiley \& Sons, Weinheim (2004).

24. F. Bolzoni, S. Goidanich, L. Lazzari, and M. Ormellese, Corros. Eng., Sci. Tech., 41, 212 (2006)

25. O. B. Al-Amoudi, M. Maslehuddin, A. N. Lashari, and A. A. Almusallam, Cem. Conc. Compos., 25, 439 (2003)

26. M. Ormellese, L. Lazzari, S. Goidanich, G. Fumagalli, and A. Brenna, Corros. Sci., 51, 2959 (2009)

27. L. Mammoliti, C. M. Hansson, and B. B. Hope, Cem. Concr. Res., 29, 1583 (1999).

28. W. Morrisand and M. Vázquez, Cem. Concr. Res., 32, 259 (2002).

29. B. Elsener, M. Büchler, F. Stalder, and H. Böhni, Corrosion, 56, 727 (2000).

30. C. K. Nmai, Cem. Conc. Compos., 26, 199 (2004).

31. A. Rosenberg, Corrosion, 56, 986 (2000).

32. P. Kern and D. Landolt, Electrochim. Acta, 47, 589 (2001)

33. F. Violetta, F. Munteanu, and F. D. Kinney, in Proceedings of the CANMET 2000, American Concrete Institute, p. 255 (2000).

34. J. K. Buffenbarger, M. A. Miltenberger, B. D. Miller, and H. L. Casal, in Proceedings International Congress, Munich, Germany, http://www.materialsweek.org/ proceedings: Sep. 2000.

35. J. P. Broomfield, Concrete, 33, 44 (1999).

36. C. K. Nmaiand and D. McDonald, in Proceedings International Symposium, Monterrey, Mexico, March 1999, RILEM, p. 104 (1999).

37. D. A. Koleva, G. Ye, J. Zhou, P. Petrov, and K. van Breugel, in RILEM Publica tions, SARL, p. 161 (2008).

38. D. A. Koleva, K. van Breugel, G. Ye, J. Zhou, G. Chamululu, and E. Koenders, in Proceedings ACI Fall Meeting, American Concrete Institute, p. 101 (2009).

39. D. A. Koleva, K. van Breugel, N. Boshkov, J. M. C. Mol, and J. H. W. de Wit, ECS Trans., 25(24), 79 (2010).

40. D. A. Koleva, ECS Trans., 28(24), 95 (2010).

41. D. A. Koleva, J. Hu, A. L. A. Fraaij, K. van Breugel, and J. H. W. de Wit, Cem Concr. Res., 37, 604 (2007).

42. A. K. Suryavanshi, J. D. Scantlebury, and S. B. Lyon, Cem. Concr. Compos., 25 , 980 (1995).

43. K. Patel, P. Bahadur, C. Guo, J. H. Ma, H. Z. Liu, Y. Yamashita, A. Khanal, and K. Nakashima, Eur. Polym. J., 43, 1699 (2007).

44. D. A. Koleva, J. Hu, J. H. W. de Wit, N. Boshkov, T. Radeva, V. Milkova, and K. van Breugel, ECS Trans., 28(24), 105 (2010).

45. D. A. Koleva, J. H. W. de Wit, K. van Breugel, and E. van Westing, J. Electrochem. Soc., 154, 52 (2007).

46. D. A. Koleva, K. van Breugel, J. H. W. de Wit, E. van Westing, N. Boshkov, and A. L. A. Fraaij, J. Electrochem. Soc., 154, E45 (2007)

47. D. A. Koleva, Z. Guo, K. van Breugel, and J. H. W. de Wit, Mater. Corros., 60, 344 (2009).

48. K. Matyjaszewski, and J. Xia, Chem. Rev, 101, 2921 (2001)

49. C. Alonso, M. Castellote, and C. Andrade, Electrochim. Acta, 47, 3469 (2002).

50. L. Li and A. A. Sagüés, Corrosion, 57, 19 (2001).

51. J. M. Miranda, J. A. González, A. Cobo, and E. Otero, Corros. Sci., 48, 2172 (2006).

52. J. R. MacDonald, Impedance Spectroscopy, Emphasizing Solid Materials and Systems, John Wiley \& Sons, New York (1987).

53. J. Xu, L. Jiang, and J. Wang, Constr. Build. Mater, 23, 1902 (2009)

54. C. Andrade, M. Keddam, X. R. Nóvoa, M. C. Pérez, C. M. Rangel, and H. Takenouti, Electrochim. Acta, 46, 3905 (2001).

55. M. Cabeza, P. Merino, A. Miranda, X. R. Nóvoa, and I. Sanchez, Cem. Concr. Res., 32, 881 (2002)

56. V. Feliú, J. A. González, and S. Feliú, J. Electrochem. Soc., 151, B134 (2004)

57. A. A. Sagüés, M. A. Pech-Canul, and A. K. M. Shahid Al-Mansur, Corros. Sci. 45, 7 (2003)

58. V. Feliú, J. A. González, C. Andrade, and S. Feliú, Corros. Sci., 40, 975 (1998).

59. A. A. Sagüés, S. C. Kranc, and E. I. Moreno, Corros. Sci., 37, 1097 (1995).

60. S. P. Harrington and T. M. Devine, J. Electrochem. Soc., 156, C154 (2009).

61. H. Hsuand and F. Mansfeld, Corrosion (Houston), 57, 747 (2001)

62. P. Zoltowski, Electroanal. Chem., 443, 149 (1998).

63. S. P. Harrington and T. M. Devine, J. Electrochem. Soc., 155, C381 (2008)

64. J. Jorcin, M. E. Orazem, N. Pébère, and B. Tribollet, Electrochim. Acta, 51, 1473 (2006)

65. G. J. Brug, A. L. G. Van Den Eeden, M. Sluyters-Rehbach, and J. H. Sluyters, $J$ Electroanal. Chem. Interfacial Electrochem., 176, 275 (1984).

66. Y. Choi, J. Kim, and K. Lee, Corros. Sci., 48, 1733 (2006).

67. F. Cui, F. J. Presuel-Moreno, and R. G. Kelly, Corros. Sci., 47, 2987 (2005).

68. E. van Westing, Ph.D. Thesis, TUD, Delft, The Netherlands (1992)

69. J. A. González, J. M. Miranda, N. Birbilis, and S. Feliú, Corrosion, 61, 37 (2005).

70. C. Andrade, L. Soler, C. Alonso, R. X. Nóvoa, and M. Keddam, Corros. Sci., 37, 2013 (1995)

71. O. Poupard, A. Aït-Mokhtar, and P. Dumargue, Cem. Concr. Res., 34, 991 (2004).

72. J. R. Scully, Corrosion, 56, 199 (2000).

73. S. Gota, E. Guiot, M. Henriot, and M. Gautier-Soyer, Phys. Rev. B, 60, 14387 (1999).

74. T. Choudhury, S. O. Saied, J. L. Sullivan, and A. M. Abbot, J. Phys. D: Appl. Phys., 22, 1185 (1989).

75. E. M. Zuyderhoff, C. M. Dekeyser, P. G. Rouxhet, and C. C. Dupont-Gillain, $J$. Colloid Interface Sci., 319, 63 (2008).

76. R. Murthy, C. E. Shell, and M. A. Grunlan, Biomaterials, 30, 2433 (2009).

77. E. Sardella, R. Gristina, G. S. Senesi, R. d'Agostino, and P. Favia, Plasma Processes Polym., 1, 63 (2004).

78. M. Shaheer Akhtar, K. K. Cheralathan, J. Chun, and O. Yang, Electrochim. Acta, 
53, $6623(2008)$

79. J. Zaanen, G. A. Sawatzky, and J. W. Allen, Phys. Rev. Lett, 55, 418 (1985)

80. Fujimori, M. Saeki, M. Taniguchi, and S. Suga, Phys. Rev. B, 34, 7318 (1986).

81. G. C. Allen, M. T. Curtis, A. J. Hooper, and P. M. Tucker, J. Chem. Soc. Dalton Trans., 14, 1525 (1974)

82. X. Li and W. Zhang, Langmuir, 22, 4638 (2006)

83. O. W. Duckworth and S. T. Martin, Geochim. Cosmochim. Acta, 68, 607 (2004).

84. J. Hu, I. M. C. Lo, and G. Chen, Sep. Purif. Technol., 58, 76 (2007).

85. A. Morel, S. I. Nikitenko, K. Gionnet, A. Wattiaux, J. Lai-Kee-Him, C. Labrugere,

B. Chevalier, G. Deleris, C. Petibois, A. Brisson, et al., ACS Nano, 2, 847 (2008).

86. M. Descostes, F. Mercier, C. Beaucaire, P. Zuddas, and P. Trocellier, Nucl. Instrum.
Methods Phys. Res. B, 181, 603 (2001).

87. M. F. Montemor, A. M. P. Simões, and M. G. S. Ferreira, Corrosion, 54, 347 (1998).

88. T. E. Pou, O. J. Murphy, V. Young, and J. M. Bockris, J. Electrochem. Soc., 131, 1243 (1984)

89. N. Guskos, Mater. Res. Bull., 37, 1051 (2002).

90. H. Oranowska and Z. Szklarska-Smialowska, Corros. Sci., 21, 735 (1981).

91. T. Zakroczymski, C.-J. Fan, and Z. Szklarska-Smialowska, J. Electrochem. Soc., 132, $2862(1985)$

92. T. Zakroczymski, C.-J. Fan, and Z. Szklarska-Smialowska, J. Electrochem. Soc., 132, $2868(1985)$ 